\title{
Regional and global modeling of aerosol optical properties with a size, composition, and mixing state resolved particle microphysics model
}

\author{
F. Yu, G. Luo, and X. Ma \\ Atmospheric Sciences Research Center, State University of New York, 251 Fuller Road, Albany, New York 12203, USA \\ Correspondence to: F. Yu (fyu@ @albany.edu)
}

Received: 21 November 2011 - Published in Atmos. Chem. Phys. Discuss.: 2 January 2012

Revised: 7 June 2012 - Accepted: 8 June 2012 - Published: 2 July 2012

\begin{abstract}
There exist large uncertainties in the present modeling of physical, chemical, and optical properties of atmospheric particles. We have recently incorporated an advanced particle microphysics (APM) model into a global chemistry transport model (GEOS-Chem) and a regional weather forecasting and chemistry model (WRF-Chem). Here we develop a scheme for calculating regional and global aerosol optical depth (AOD) from detailed aerosol information resolved by the APM model. According to GEOS-Chem-APM simulations, in most parts of the globe, the mass of secondary species resides mainly within secondary particles (60-90\%), but in certain regions a large fraction (up to $50-80 \%$ ) can become coated on various primary particles. Secondary species coated on black carbon and primary organic carbon particles significantly increase the size and hygroscopicity of these particles and thus impact their optical properties. The GEOS-Chem-APM model captures the global spatial distributions of AOD derived from AERONET, MODIS, and MISR measurements, generally within a factor of $\sim 2$. Our analysis indicates that modeled annual mean AODs at all sky and clear sky conditions differ by $\sim 20 \%$ globally averaged and by $>50 \%$ in some regions. The time series of WRF-Chem-APM predicted AOD over the northeastern United States in June 2008 have been compared to those from seven AERONET sites. Overall, the model mostly captures the absolute values as well as the variations of AOD at the AERONET sites (including dramatic changes associated with the crossing of high AOD plumes). Both GEOSChem and WRF-Chem simulations indicate that AOD over the northeastern US is dominated by secondary particles and have large spatiotemporal variations.
\end{abstract}

\section{Introduction}

Tropospheric aerosols impact climate directly by scattering and absorbing radiation and indirectly by acting as cloud condensation nuclei to affect cloud properties and precipitation. There exist large uncertainties in both direct and indirect radiative forcing (RF) of atmospheric aerosols (IPCC, 2007; Chin et al., 2009). The optical properties and thus the direct RF (DRF) of atmospheric aerosols depend on a number of parameters such as particle size distribution, composition, hygroscopicity, refractive index, and mixing state. Modeling of these aerosol parameters, as well as the processes controlling their spatiotemporal variations, by various global aerosol models differs significantly, which is the key source of uncertainties in predicted aerosol optical properties and DRF (e.g., Kinne et al., 2006; Schulz et al., 2006; Textor et al., 2007).

Most climate models treat $\mathrm{BC}$ particles as externally mixed (e.g., Textor et al., 2007; Koch et al., 2009) but some global aerosol models (e.g., Stier et al., 2005; Bauer et al., 2008; Spracklen et al., 2008) resolve the internal mixtures of $\mathrm{BC}$ with other components. It has been well recognized that the mixing state of $\mathrm{BC}$ particles affects absorption and RF (e.g., Ackerman and Toon, 1981; Bond et al., 2006). Bond et al. (2006) investigated theoretically the increase in absorption when $\mathrm{BC}$ particles, within a realistic range of sizes, are internally mixed with other (non-absorbing) materials. In particular they showed that total absorption increased (by a factor of up to 2-4) when mixing (or coating) is resolved whereas models that ignore such mixing underestimate $\mathrm{BC}$ positive RF. By comparing results from AeroCom models and observations, Koch et al. (2009) showed that AeroCom models under-predicted absorption AOD (AAOD) 
but overestimated surface and upper atmospheric BC concentrations at lower latitudes, and concluded that most models are underestimating BC absorption and should improve estimates for refractive index, particle size, and optical effects of BC coating. One further important factor affecting DRF is the particle hygroscopicity which depends on composition and mixing state, and it is critical to calculate particle hygroscopic growth online because of non-linear dependence of water uptake on $\mathrm{RH}$.

Textor et al. (2007) showed that harmonization of aerosol sources has only a small impact on the simulated intra-model diversity of the global aerosol burden and optical properties, and pointed to the need for a better understanding and representation of aerosol life cycles at each process level. Chin et al. (2009) also identified the need to improve the accuracy and capability of model simulation of aerosols (including components and atmospheric processes) as one of the key research priorities in order to reduce the uncertainty in the assessment of aerosol-climate impacts.

Particles in the troposphere either come from direct emission (i.e., primary particles) or in-situ nucleation (i.e, secondary particles). The aging process transforms these particles into different sizes, mixing states and compositions. Some particles contain solid cores yet others do not, and the amount of secondary species coated on primary particles has large spatiotemporal variations. While particles without solid cores can be treated as internally and well mixed, Bond et al. (2006) recommended that the treatment of particles containing absorbing cores as internally well mixed should be avoided. Seeking to improve the representation of major processes affecting the aerosol properties important for their climate impacts in 3-D models, we have developed a size-resolved (sectional), advanced particle microphysics (APM) model and have successfully incorporated it into a global chemistry transport model (GEOS-Chem) (Yu and Luo, 2009) and a regional weather forecasting and chemistry model (WRF-Chem) (Luo and Yu, 2011). We have designed and implemented a number of computationally efficient schemes which enable the APM model to capture the main particle properties (sizes, compositions, coating of primary particles by secondary species, etc.) important for their RF while keeping the computational costs affordable. APM treats particles of different types (secondary, BC, dust, sea salt, primary organic carbon - POC) as semi-externally mixed, i.e., (1) it separates secondary and four types of primary particles, and (2) it explicitly predicts the spatiotemporal variations of the mass of secondary species coated on each type of primary particle as a result of coagulation, condensation, and equilibrium uptake. Details of the treatment of secondary organic and inorganic species in APM can be found in Yu and Luo (2009) and Yu (2011).

The main objective of this work is to investigate aerosol optical properties based on size, composition, and mixing state resolved APM model. A computationally efficient scheme, using lookup tables, is designed and developed to calculate online the aerosol optical properties from detailed particle property information predicted by APM. In Sect. 2, we investigate the dependence of optical properties on key parameters and describe the lookup tables constructed. Some key aerosol properties predicted by APM that are relevant to optical property calculation are described in Sect. 3. Section 4 presents simulated global and regional aerosol optical properties with GEOS-Chem-APM and WRF-ChemAPM respectively, as well as comparisons with measurements. Summary and discussion are given in Sect. 5. The calculated aerosol optical properties provide inputs to a radiative transfer module and the resulting aerosol direct RF is reported in a separate paper (Ma et al., 2012). Although many papers have investigated the role of nucleated particles on CCN/indirect forcing (Spracklen et al, 2008; Merikanto et al., 2009; Yu and Luo, 2009; Wang and Penner; 2010), this is (to our knowledge) the first to attempt to quantify the contribution to aerosol optical depth of the secondary (nucleated) particles.

\section{Particle optical properties: controlling parameters and lookup tables}

The key particle optical properties used for DRF calculation include extinction efficiency $\left(Q_{\text {ext }}\right)$, single scattering albedo $(\omega)$, and asymmetry parameter $(g)$. The absorption extinction efficiency $\left(Q_{\text {abs }}\right)$ can be calculated from $Q_{\text {ext }}$ and $\omega$ as $Q_{\mathrm{abs}}=Q_{\mathrm{ext}} \times(1-\omega)$. The values of $Q_{\mathrm{ext}}, \omega$, and $g$ depend on wavelength $(\lambda)$, core diameter $\left(d_{\text {core }}\right)$, shell diameter $\left(d_{\text {shell }}\right)$, and real $\left(k_{\mathrm{r}}\right)$ as well as imaginary $\left(k_{\mathrm{i}}\right)$ components of refractive index $\left(k=k_{\mathrm{r}}-k_{\mathrm{i}} i\right)$ for both core and shell, and can be calculated with widely used Mie theory. The core-shell model of Ackerman and Toon (1981), which can use either the volume averaged refractive indices or the shell/core configuration, is employed in this study.

To reduce computation cost for 3-D online calculation, we have designed and generated lookup tables so that $Q_{\text {ext }}, \omega$, and $g$ values can be determined efficiently. According to the properties of aerosols resolved by APM, three lookup tables have been developed: the first for particles without solid absorbing cores (i.e., secondary particles, coated sea salt, and coated POC), the second for coated BC, and the third for coated dust. For coated $\mathrm{BC}$ and dust particles, the core-shell model assumes that BC and dust have a spherical core, surrounded by a spherical shell composed of all the other nonor less-absorbing secondary species and water. For hydrated (i.e., wet) secondary particles, coated sea salt particles, and coated primary organic particles, we set the core size to zero and use the volume-average of refractive index to calculate the optical properties of particles of given wet sizes. For refractive index of $\mathrm{BC}$ core, we use the value recommended by Bond et al. (2006) which is $1.85-0.71 i$. For dust core, a wavelength dependent parameterization of refractive index presented in Balkanski et al. (2007) is adapted. The 
Table 1. The range of each dependent variable dimension, the total number of points in each dimension, and the values at each point for shortwave aerosol optical property look-up tables for particles without solid cores, particles with BC cores, and particles with dust cores.

\begin{tabular}{|c|c|c|c|c|}
\hline & & Range & $\begin{array}{l}\text { Total \# } \\
\text { of points }\end{array}$ & Values at each point \\
\hline \multicolumn{2}{|l|}{$\lambda(\mu \mathrm{m})$} & $0.34-3.19$ & 16 & $\begin{array}{l}\lambda(i)=0.34,0.38,0.443,0.469,0.5,0.554,0.645,0.675 \\
0.865,0.94,1.02,1.24,1.64,1.785,2.13,3.19 ; i=1,16\end{array}$ \\
\hline \multirow{3}{*}{$d_{\text {core }}(\mu \mathrm{m})$} & No core & 0 & 1 & $d_{\text {core }}(j)=0, j=1$ \\
\hline & BC-core & $0.01-1$ & 21 & $d_{\text {core }}(j)=0.01 \times 10^{(j-1) / 10}, j=1,21$ \\
\hline & Dust-core & $0.05-50$ & 61 & $d_{\text {core }}(j)=0.05 \times 10^{(j-1) / 20}, j=1,61$ \\
\hline \multirow{3}{*}{$d_{\text {shell }}(\mu \mathrm{m})$} & No core & $0.02-20$ & 91 & $d_{\text {shell }}(l)=0.02 \times 10^{(l-1) / 30}, l=1,91$ \\
\hline & BC-core & $0-1$ & 32 & $d_{\text {shell }}(1)=0, d_{\text {shell }}(l)=0.001 \times 10^{(l-2) / 10}, l=2,32$ \\
\hline & Dust-core & $0-1$ & 32 & $d_{\text {shell }}(1)=0, d_{\text {shell }}(l)=0.001 \times 10^{(l-2) / 10}, l=2,32$ \\
\hline$k_{\mathrm{r}}$ & & $1.33-1.53$ & 6 & $k_{\mathrm{r}}(m)=1.33+0.04 \times(m-1), m=1,6$ \\
\hline$k_{\mathrm{i}}$ & & $10^{-6}-10^{0}$ & 17 & $k_{\mathrm{i}}(1)=10^{-6}, k_{\mathrm{i}}(n)=0.001 \times 10^{(n-2) / 5}, n=2,17$ \\
\hline
\end{tabular}

volume-averaged refractive indices for species other than $\mathrm{BC}$ and dust are calculated based on the composition predicted by APM. The particles are assumed to be spherical where as non-spherical effect is not considered in the present study.

Table 1 gives the ranges of each dependent variable dimension, total number of points in each dimension, and values at each point for the three shortwave look-up tables corresponding to particles without solid absorbing cores, coated BC, and coated dust particles, respectively. The values of wavelength are selected based on the wavelengths of AERONET, MODIS, MISR, and wavelength bands of a radiative transfer code used for DRF calculation (Ma et al., 2012). The selected parameter ranges cover the majority of conditions in the troposphere relevant to atmospheric particles simulated by APM. The range and resolution in each parameter space can be extended in the future if needed. Aerosol optical properties at longwave $(>\sim 4 \mu \mathrm{m})$ is calculated only for dust particles as it is negligible for all other particles. For large dust particles, the coating effect is negligible and can be ignored. Table 2 gives the ranges of each dependent variable dimension, total number of points in each dimension, and values at each point for the longwave look-up table for dust particles.

For any given values of $\lambda, d_{\text {core }}, d_{\text {shell }}, k_{\mathrm{r}}$ and $k_{\mathrm{i}}$ within the ranges specified in Tables 1 and 2, $Q_{\text {ext }}, \omega$, and $g$ can be obtained using the look-up table with an efficient multiplevariable interpolation scheme described in Yu (2010). For present application, the wavelengths of interest do not change during the simulation, and the values of $\lambda$ in the lookup tables are selected in such a way so that no interpolation with regard to wavelength is needed to obtain the optical properties for comparison with corresponding observations from AERONET, MODIS and MISR, and for input to a radiative
Table 2. The range of each dependent variable dimension, the total number of points in each dimension, and the values at each point for long-wave aerosol optical property look-up tables for dust particles.

\begin{tabular}{llll}
\hline & Range & $\begin{array}{l}\text { Total \# } \\
\text { of points }\end{array}$ & Values at each point \\
\hline $\begin{array}{l}\lambda \\
(\mu \mathrm{m})\end{array}$ & $4.0-40$ & 41 & $\begin{array}{l}\lambda(i)=4.0 \times 10^{(i-1) / 40} \\
i=1,41\end{array}$ \\
\hline $\begin{array}{l}D_{\text {dust }} \\
(\mu \mathrm{m})\end{array}$ & $0.05-50$ & 31 & $\begin{array}{l}D_{\text {dust }}(j)=0.05 \times 10^{(j-1) / 10}, \\
j=1,31\end{array}$ \\
\hline
\end{tabular}

transfer code. Nevertheless, for other application and if necessary, interpolation with regard to $\lambda$ can be performed.

Figure 1 shows the dependence of $Q_{\text {ext }}, Q_{\text {abs }}=Q_{\text {ext }} \times$ $(1-\omega), \omega$, and $g$ on $\lambda$ for the three particle types. In addition to refractive index, particle optical properties largely depend on the size parameter $x$ which can be defined as $x=r / \lambda$ where $r$ is the particle radius. For weak absorbing particles, $Q_{\text {ext }}$ monotonically increases with $x$ when $x<1$ and peaks around $x$ value of unity. $Q_{\text {ext }}$ oscillates around the values of 2 when $x>1$ and approach 2 when $x \gg 1$. For given particle sizes of $0.4 \mu \mathrm{m}, Q_{\text {ext }}, \omega$, and $g$ generally decrease with increasing $\lambda$ at visible and near infrared wavelength (Fig. 1a). Because of refractive index variations, different particle types behave differently. While both $Q_{\text {ext }}$ and $Q_{\text {abs }}$ decrease with $\lambda$, the fraction of $Q_{\text {ext }}$ due to absorption (i.e., $1-\omega$ ) increases with $\lambda$ (Fig. 1b). For same size particles $\left(d_{\text {core }}+d_{\text {shell }}\right)$, the three types of $0.4 \mu \mathrm{m}$ particles have similar extinction coefficients at visible wavelengths but the particles with $\mathrm{BC}$ cores only have much larger absorption and extinction coefficients at infrared wavelengths. 

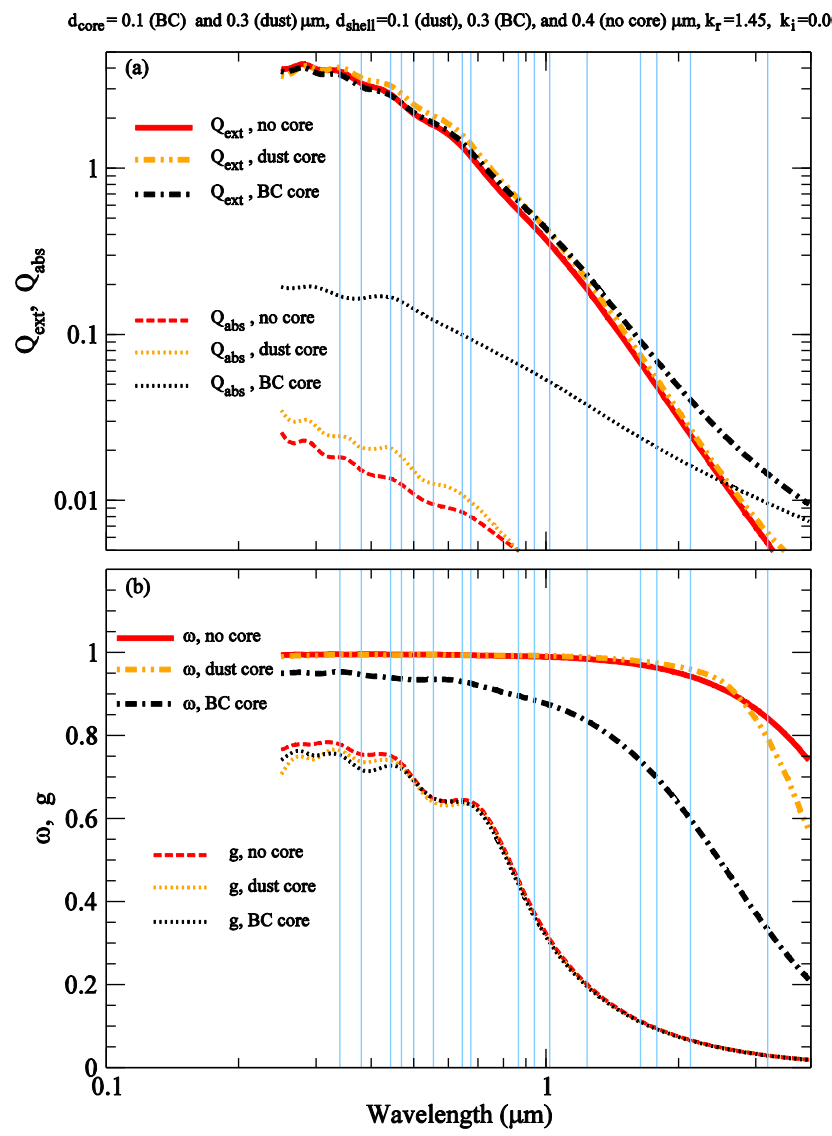

Fig. 1. Dependence of $Q_{\text {ext }}, Q_{\mathrm{abs}}, \omega$, and $g$ on wavelength ( $\lambda$ ) for three types of $0.4 \mu \mathrm{m}$ particles under selected conditions, with the 16 wavelength values in the lookup tables marked as vertical lines.

In Fig. 2, the values of $Q_{\text {ext }}$ and $Q_{\text {abs }}$ interpolated from the look-up tables, as a function of $d_{\text {core }}, d_{\text {shell }}, k_{\mathrm{r}}$ and $k_{\mathrm{i}}$ under selected conditions, are plotted along with those calculated with the full Mie model, showing good agreement between interpolated and corresponding full model values. For each curve, only one parameter (shown in x-axis) is changing. Figure 2a shows the dependence of $Q_{\text {ext }}$ and $Q_{\text {abs }}$ on the depth of the shell layer $\left(d_{\text {shell }}\right)$ under given (and fixed) values of $\lambda$, $d_{\text {core }}, k_{\mathrm{r}}$, and $k_{\mathrm{i}}$. Coating has little effect when $d_{\text {shell }} \ll d_{\text {core }}$ (Fig. 2a) but becomes important when $d_{\text {shell }}$ is comparable to or larger than $d_{\text {core }}$. For particles with no solid cores, their extinction efficiency increases dramatically as their size increases from $\sim 50$ to $\sim 500 \mathrm{~nm}$. Similarly, the increase of small $\mathrm{BC}$ particles from $\sim 100$ to $\sim 500 \mathrm{~nm}$ due to coating substantially enhances their extinction efficiency. The significant effect of sizes on the extinction efficiency of particles smaller than $\sim 500 \mathrm{~nm}$ (dominated by secondary particles, $\mathrm{BC}$, and POC) highlights the importance to explicitly resolve the size evolution of these particles for accurate prediction of their AODs and DRF. Secondary particle size distributions are controlled by nucleation, condensation, coagulation, deposition, equilibrium uptake, and aqueous chemistry, while those of BC and POC particles are largely determined by their initial sizes, coating, equilibrium uptake, coagulation, and deposition. To explicitly resolve these processes in 3-D models is challenging, but necessary in order to reduce uncertainty in aerosol RF calculations.

Figure $2 \mathrm{~b}$ shows the dependence of their optical properties on the sizes of cores for those particles with solid cores (i.e., $\mathrm{BC}$ and dust particles). At the assumed $d_{\text {shell }}(0.1 \mu \mathrm{m}$ for dust and BC), $Q_{\text {ext }}$ and $Q_{\text {abs }}$ generally increase with $d_{\text {core }}$ until reaching their peak. Most dust particles in the atmosphere are likely larger than $0.5 \mu \mathrm{m}$ thus $Q_{\text {ext }}$ is already in the domain of peak $Q_{\text {ext }}$ values. The picture is very different for $\mathrm{BC}$ particles as most are smaller than $0.2 \mu \mathrm{m}$. As a result, the optical properties and RF of BC particles are sensitive to the sizes of $\mathrm{BC}$ particles, highlighting the necessity in reducing the uncertainty in the sizes of BC particles in models. It is clear from Fig. $2 \mathrm{~b}$ that, as expected, particles with $\mathrm{BC}$ core have much higher $Q_{\text {abs }}$ and that $Q_{\text {abs }}$ contributes to around $50 \%$ of $Q_{\text {ext }}$ when $d_{\text {core }}>\sim 0.1 \mu \mathrm{m}$.

The secondary species coated on BC and dust particles generally have very small imaginary parts of their refractive indices, thus they have small absorption in the visible light range. Nevertheless, there exist some organic compounds that absorb strongly (i.e., brown carbon, with the imaginary part of their refractive index reaching up to 0.27) (Alexander et al., 2008). The effects of refractive indices $\left(k=k_{\mathrm{r}}-k_{\mathrm{i}} i\right)$ of shell species on optical properties at selected conditions are given in Fig. 2c and d. With a fixed $k_{\mathrm{i}}, Q_{\text {ext }}$ and $Q_{\text {abs }}$ increase monotonically with $k_{\mathrm{r}}$ while $Q_{\text {ext }}$ can be more than doubled when $k_{\mathrm{r}}$ increases by $\sim 15 \%$ (from 1.33 to 1.53 ). For particles with $\mathrm{BC}$ or dust cores, the impact of $k_{\mathrm{i}}$ values on $Q_{\mathrm{abs}}$ is small when $k_{\mathrm{i}}<0.001$ but is substantial when $k_{\mathrm{i}}>0.001$. For particles without cores, $Q_{\mathrm{abs}}$ is sensitive to $k_{\mathrm{i}}$ although $Q_{\text {abs }}$ is negligible when $k_{\mathrm{i}}<0.001$. If $k_{\mathrm{i}}$ increases to $\sim 0.1$, particles of all types have a much stronger $Q_{\text {abs }}$, although the corresponding impact on $Q_{\text {ext }}$ is relatively small under the conditions considered in the figure. A number of recent studies (e.g., Alexander et al., 2008; Shapiro et al., 2009) indicate that certain secondary organic aerosols (SOA) can react with sulfate and form absorbing compounds (i.e., brown carbon). Figure $2 \mathrm{~d}$ suggests that the increase of $k_{\mathrm{i}}$ associated with the formation of brown carbon could substantially increase the aerosol overall absorption including coated BC particles. The significant impact of refractive indices of water soluble species on aerosol optical properties calls for a robust representation of chemical compositions and hygroscopic growth of various particles in the models.

\section{Particle composition, mixing state, coating, and hygroscopic parameter $(\kappa)$ predicted by APM}

In the real atmosphere, the degree of the mixing states of particles varies with time and location. The size-resolved APM is designed to explicitly predict the spatiotemporal variations 
(a) $\mathrm{d}_{\text {core }}=0.1$ (BC) and 0.5 (dust) $\mu \mathrm{m}, \mathrm{k}_{\mathrm{r}}=1.45, \mathrm{k}_{\mathrm{i}}=0.001$

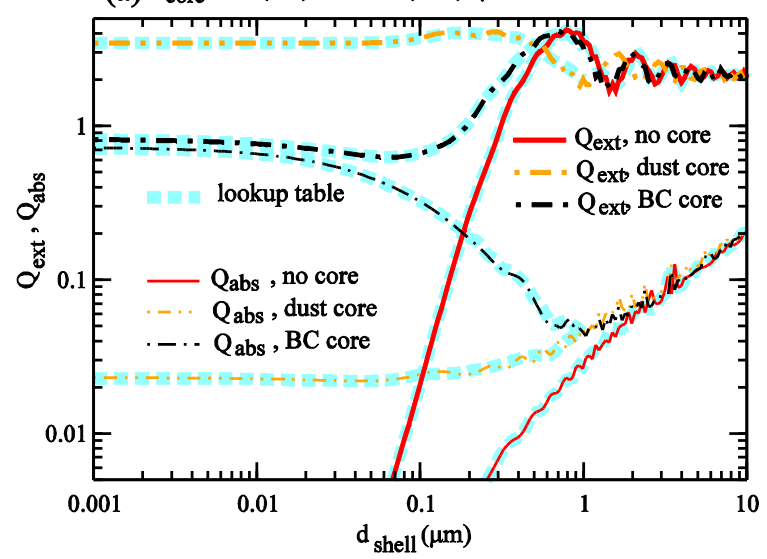

(c) $d_{\text {core }}=0.1$ (BC) and 0.5 (dust) $\mu \mathrm{m}$,

$\mathrm{d}_{\text {shell }}=0.1$ (dust) and 0.3 (no core, $\left.B C\right) \mu \mathrm{m}, \mathrm{k}_{\mathrm{i}}=0.01$

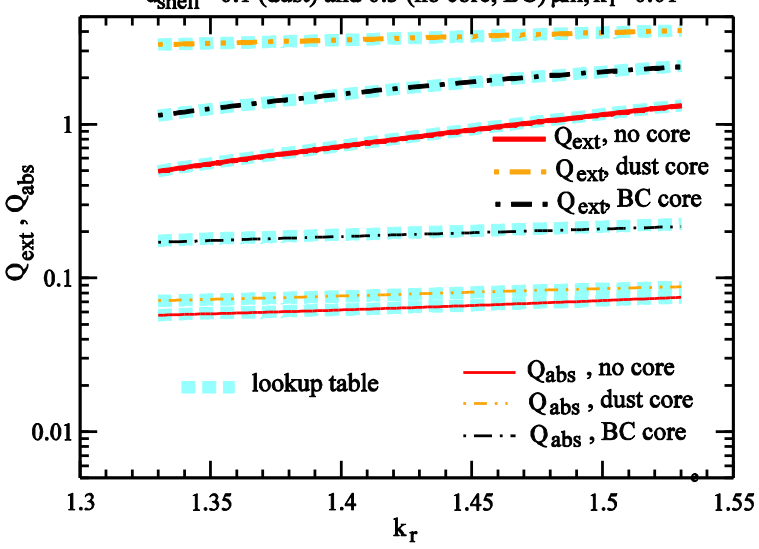

(b) $\mathrm{d}_{\text {shell }}=0.1$ (dust, BC) $\mu \mathrm{m}, \mathrm{k}_{\mathrm{r}}=1.45, \mathrm{k}_{\mathrm{i}}=0.001$

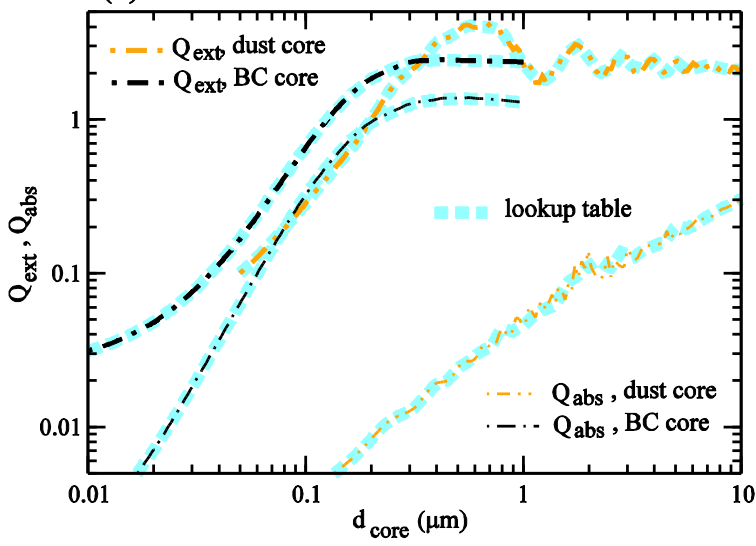

(d) $d_{\text {core }}=0.1$ (BC) and 0.5 (dust) $\mu \mathrm{m}$, $\mathrm{d}_{\text {shell }}=0.1$ (dust) and 0.3 (no core, $\mathrm{BC}$ ) $\mu \mathrm{m}, \mathrm{k}_{\mathrm{r}}=1.45$

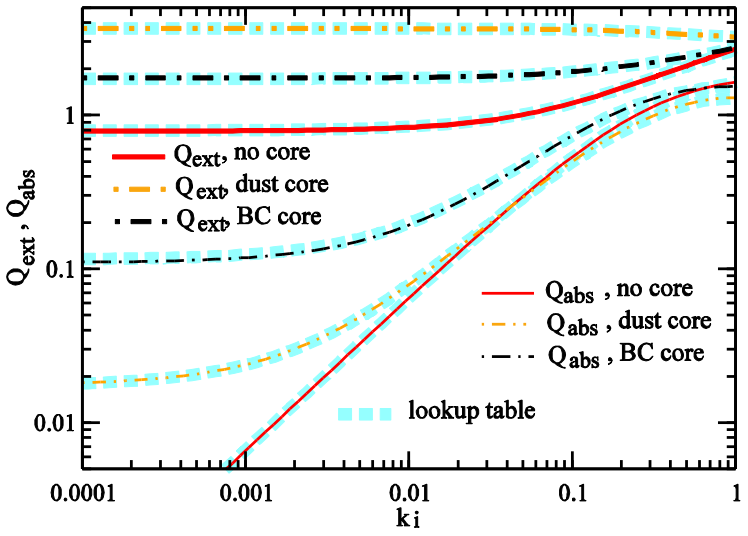

Fig. 2. Dependence of $Q_{\text {ext }}$ and $Q_{\text {abs }}$ on $d_{\text {core }}, d_{\text {shell }}, k_{\mathrm{r}}$ and $k_{\mathrm{i}}$ under selected conditions. The thick dashed cyan lines are values interpolated from the look-up tables while all other lines are values calculated with the full Mie model.

in the degree of particle mixing which is important for their climatic impact through both direct and indirect RF. Similar approaches have been used in other bin-resolved aerosol models (e.g., Jacobson, 2001; Pierce et al., 2007).

As mentioned earlier, APM separates secondary particles from four different types of primary particles while it explicitly predicts the amount of secondary species coated on each type of primary particle (Yu and Luo, 2009). The present version of the APM module incorporated in both GEOS-Chem and WRF-Chem employs 40 bins for secondary particles to cover the dry diameter size range of 0.0012 to $12 \mu \mathrm{m}, 20$ bins for sea salt to cover the dry diameter size range of 0.012 to $12 \mu \mathrm{m}$, and 15 bins for dust particles to cover size range of 0.03 to $50 \mu \mathrm{m}$. Because of large differences in the median sizes of BC and POC from fossil fuel combustion and biomass burning, we employ two log-normal modes (one for fossil fuel and another for biomass burning) to represent hydrophobic BC and another two log-normal modes for hydrophilic BC (Yu and Luo, 2009). Similarly, 4 log-normal modes are used to represent hydrophobic and hydrophilic
POC. The present APM treats BC and POC as externally mixed, which may lead to some uncertainties in the calculated optical properties as some of BC and POC may be emitted as or become internally mixed.

The major secondary species considered in the APM model include sulfate, ammonium, nitrate, low volatile SOA (LV-SOA), semi-volatile SOA (SV-SOA), and mediumvolatile SOA (MV-SOA). Sulfate formation is through ionmediated nucleation (IMN) (Yu, 2010; Yu and Turco, 2011), $\mathrm{H}_{2} \mathrm{SO}_{4}$ vapor condensation and aqueous chemistry, while the amount of ammonium and nitrate associated with sulfate is determined based on thermodynamic equilibrium according to ISORROPIA II (Fountoukis and Nenes, 2007). The condensation of LV-SOA on all types of particles is explicitly simulated (Yu, 2011) and the uptake of SV-SOA and MV-SOA is calculated based on partitioning theory (Chung and Seinfeld, 2002). Detailed discussion of SOA treatment in the model can be found in Yu (2011). Water uptake at any given RH is calculated based on the particle's 
hygroscopic parameter which depends on the composition using the scheme given in Petters and Kreidenweis (2007).

The APM model employs a number of computationally efficient schemes including: (1) usage of pre-calculated lookup tables for nucleation rates and coagulation kernels; (2) variable size ranges and bin resolutions for particles of different types; (3) variable and optimized time steps for the coagulation calculations; (4) the coating of primary particles by sulfate and LV-SOA are tracked using two tracers (one for sulfate and the other for LV-SOA) for each type of primary particle; (5) nitrate and ammonium associated with sulfate are calculated based on thermodynamic equilibrium, and (6) SVSOA and MV-SOA formation associated with the presence of LV-SOA in the particles are calculated based on the partitioning theory. These schemes enable the APM model to capture the main properties of atmospheric particles important for their direct and indirect RF while keeping the computational costs affordable.

In the past, a large set of land-, ship-, and aircraft-based measurements of particle number concentrations around different parts of the globe have been used to evaluate the ability of the APM model in capturing the spatial distribution of the number concentrations of particles larger than $\sim 3 \mathrm{~nm}$ (Yu et al., 2010) and 10 nm (Yu and Luo, 2009; Yu et al., 2010) as well as $\mathrm{CCN}$ at water supersaturation ratio of $0.4 \%$ (Yu et al., 2012). The model can capture the absolute values of particle number concentrations (within a factor of two for most of sites around the globe) as well as their spatial variations (for example, correlation coefficient for CCN up to 0.94 , Yu et al., 2012). The evaluation of model predicted size distributions and chemical compositions has been quite limited, partially due to the lack to long-term measurements in rural areas (horizontal resolution of our global modeling is not high enough to resolve urban centers). In Yu (2011), we compared particle size distribution evolution during a period of one month predicted by GEOS-Chem-APM with those observed at Hyytiala, Finland and showed that the overall agreement between simulated and observed size distributions is reasonable after the condensation of low-volatile secondary organics is considered. A comparison of simulated secondary organic aerosol (SOA) mass concentrations with those observed at 10 rural sites with Aerosol Mass Spectrometer (as reported in Jimenez et al., 2009) showed that, on average, the modeled SOA mass at these sites are slightly lower than those observed (by $\sim 29 \%$ ). Ma et al. (2012) have compared simulated and observed sulfate and BC concentrations. Overall, the simulated sulfate concentrations agree well with the observations, particularly in the United States. The simulated BC over the United States and Europe are slightly lower than observations, but overall still in good agreement. However, the simulated BC concentrations are significantly lower than observations in Asia. Further evaluation of the simulated aerosol properties relevant for AOD (such as composition, water uptake, vertical distributions, temporal variations, etc.) are still needed to further assess and improve the perfor- mance of the aerosol model. Satellites provide unique longterm measurements ( $>1 \mathrm{yr}$ ) with global coverage which are useful to evaluate large scale aerosol modeling. One main objective of this work is to evaluate aerosol optical properties based on size, composition, and mixing state resolved APM model by comparing with MODIS, MISR, and AERONET data. Since AOD depends on particle size distribution, composition, mixing state, and hygroscopicity, a comparison of modeled AOD with observations that have large spatial coverage and long duration can help to assess the ability of the model in capturing important aerosol properties.

We use GEOS-Chem-APM to illustrate the global annual mean aerosol properties (composition, coating, mixing state, and hygroscopic parameter) resolved by APM. The global simulations presented below are based on a one-year simulation (October 2005-December 2006, with the first 3 months as spin-up) using v8-03-02 of GEOS-Chem (e.g., Bey et al., 2001) +APM, with nucleation rates predicted by the IMN mechanism (Yu, 2010) and the condensation of low volatile secondary organic gases from successive oxidation (Yu, 2011) taken into account. The effect of sea surface temperature on sea salt emission is considered, using the empirical formula given by Jaeglé et al. (2011). The horizontal resolution is $4 \times 5^{\circ}$ and there are 47 vertical layers in the model (surface to $0.01 \mathrm{hpa}$ ).

Secondary species (SS, composed of sulfate, ammonium, nitrate, and SOAs) are important components of atmospheric species. Figure 3 shows the horizontal distribution of the column burden of total SS (i.e., sulfate + ammonium + nitrate + SOAs), and the fractions of these species remaining in secondary particles (SP) and coated on each type of primary particles. Annual mean SS burden is higher over major continents $\left(>10 \mathrm{mg} \mathrm{m}^{-2}\right)$ with highest value exceeding $70 \mathrm{mg} \mathrm{m}^{-2}$ over some areas of eastern China. SS burdens in the Arctic and Antarctic regions are in the range of 7$10 \mathrm{mg} \mathrm{m}^{-2}$ and $1-3 \mathrm{mg} \mathrm{m}^{-2}$, respectively. SS burdens over oceans are in the range of $1-10 \mathrm{mg} \mathrm{m}^{-2}$, relatively higher in the outflow regions of major continents and lower in the tropics. Figure 3b shows that SS reside mainly in SPs (60-90\%) in most parts of the globe where SPs are the dominant contribution to the condensation sink, but a large fraction (up to $50-80 \%$ ) can become coated on various primary particles in certain regions such as Asia, South America, South Africa, and Southern Oceans where emission and concentrations of primary particles are high (Fig. 3c-f). Globally averaged, $\sim 71.3 \%$ of SS resides in SP while $1.0 \%, 2.0 \%, 8.6 \%$, and $17.1 \%$ of SS are coated on sea salt, dust, BC, and POC particles, respectively. The coated SS has negligible effect on the size and hydroscopicity parameter $(\kappa)$ of sea salt and dust particles due to the large size and mass burden of these particles. However, the coating has significant impact on the sizes and $\kappa$ of BC and POC particles as shown in Fig. 4, which gives the ratio of total dry mass (core component + coated $\mathrm{SS}$ ) to the mass of the core components as well as $\kappa$ values for SP, coated BC, and coated POC, averaged within the first 
(a) 2006 burden of total secondary species $\left(\mathrm{mg} / \mathrm{m}^{2}\right)$

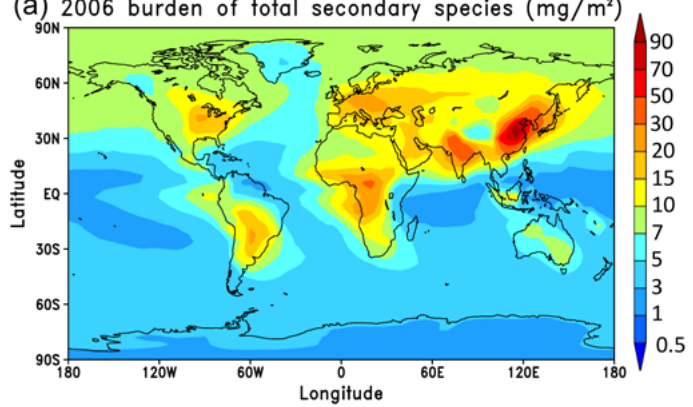

(c) 2006 Fraction of SS burden coated on seasalt

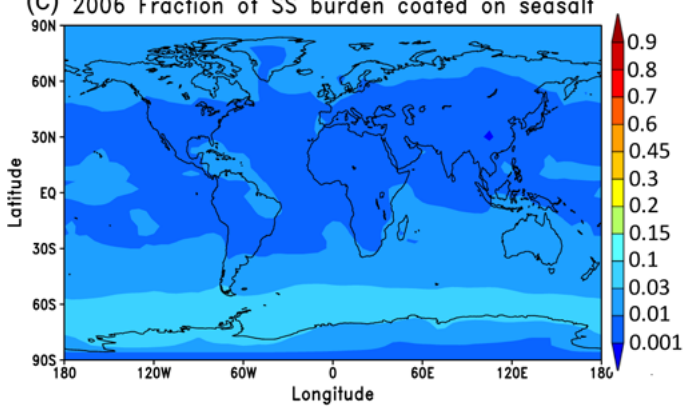

(e) 2006 Fraction of SS burden coated on BC

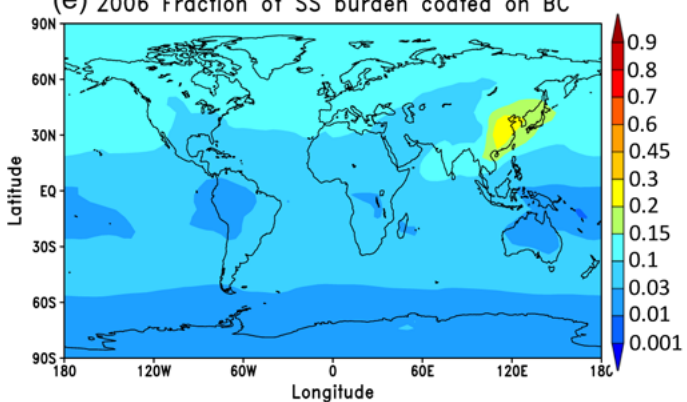

(b) 2006 Fraction of SS burden in SP

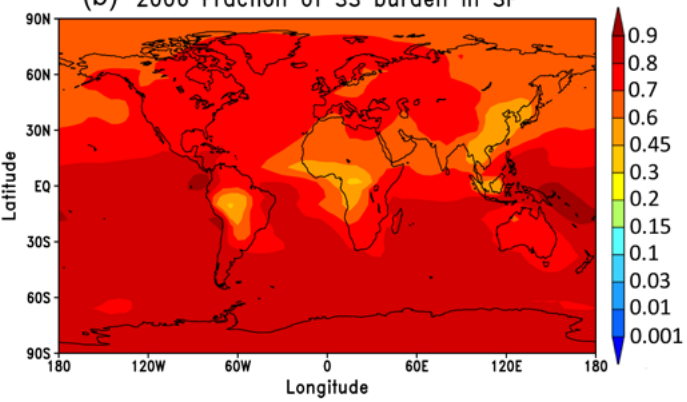

(d) 2006 Fraction of SS burden coated on dust
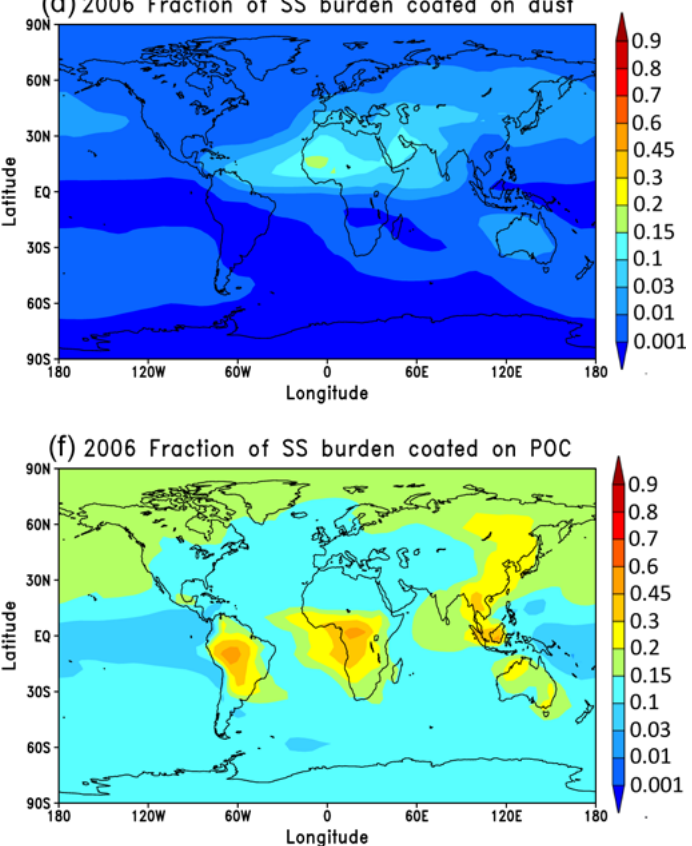

Fig. 3. Horizontal distribution of the column burden of total secondary species (SS, composed of sulfate, ammonium, nitrate, and SOAs), and the fractions of these species remaining in secondary particles (SP) and coated on each type of primary particles (dust, sea salt, BC, POC).

$2 \mathrm{~km}$ of atmosphere above surface. The $\kappa$ values for the single components follow those given in Petters and Kreidenweis (2007).

Figure $4 \mathrm{a}$ shows that over the major continents, sulfate contributes $\sim 10-50 \%$ of the total SP mass. Over the oceans and polar regions, sulfate becomes more abundant $(>50 \%)$ in the SPs. The SP mass is dominated by SOA in South Africa and South America due to large biogenic VOC emission there. The annual mean $\kappa$ of SP is generally above 0.6 except over South Africa and South America where relatively low $\kappa$ SOA species dominate. Pure BC particles are hydrophobic $(\kappa=0)$ but become hydrophilic as a result of aging (or coating). Figure $4 \mathrm{~b}$ and $\mathrm{c}$ shows that the mass of coated SS is a factor of two or more higher than that of BC cores in most of the lower troposphere, except in low latitude regions of the Southern Hemisphere where the concentrations of inorganic species are low. The coating significantly increases the $\kappa$ values of BC particles (Fig. 4d) and, as expected, the spatial distribution of $\kappa$ is similar to that of the coated mass. Over the main continents in the Northern Hemisphere (NH), the $\kappa$ value of coated BC particles is generally in the range of $0.4-0.5$ but is below 0.3 over the continents in the South Hemisphere ( $\mathrm{SH})$. As BC particles become wellaged or mixed during their transportation away from source regions, $\kappa$ values are generally higher over the oceans and polar regions. Figure $4 \mathrm{e}$ shows that the ratio of the mass of coated POC to that of core POC is generally between 1.5 and 3 in the lower troposphere. While the total amount of SS coated on POC is larger than that coated on BC (Fig. 3e, f), the mass ratio of coated mass to the core mass is smaller for POC because of larger POC mass emission and concentration. Pure POC has $\kappa$ of 0.1 , and the coating increases the annual mean $\kappa$ of coated POC to $\sim 0.3-0.5$ in most parts of the $\mathrm{NH}$ and to $\sim 0.2-0.3$ over major continents in the SH. Similar to those of BC and SP particles, $\kappa$ values for coated POC are generally higher over the oceans and polar regions. It should be noted that present study does not consider the interaction of BC and POC. In the real atmosphere, some fractions of 
(a) 2006 L1-14 Ratio of total SP mass to SP_sulf_mass

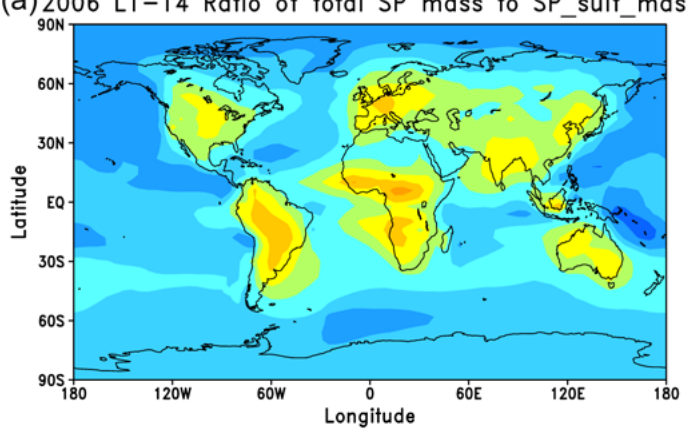

(c) 2006 L1-14 (M_BC + Mcoated)/M_BC

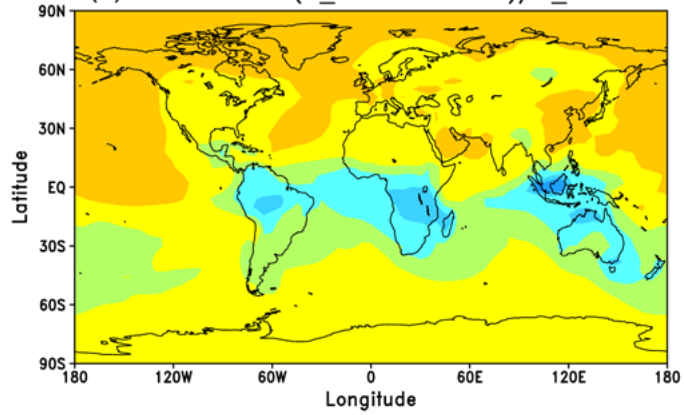

(e) 2006 L1-14 (M_POC + Mcoated)/M_POC

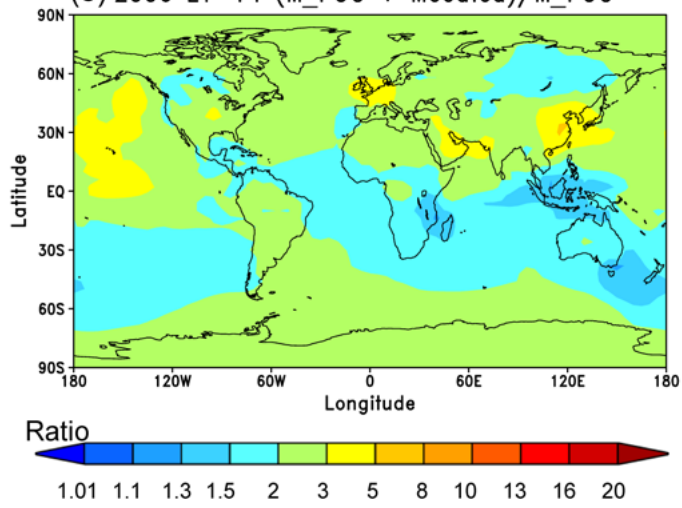

(b) 2006 L1-14 kappa of SP

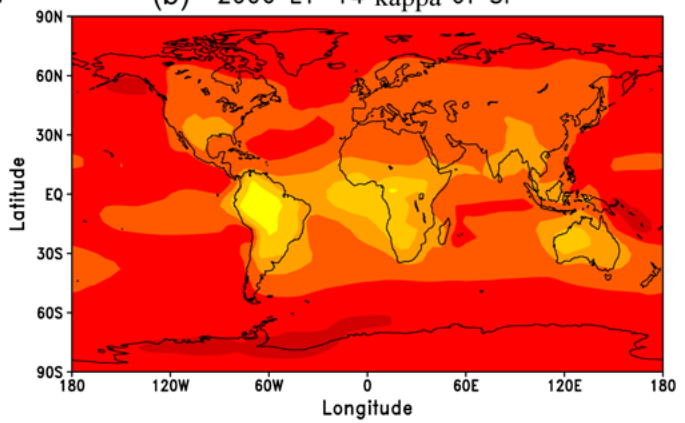

(d) 2006 L1-14 kappa of coated BC particles

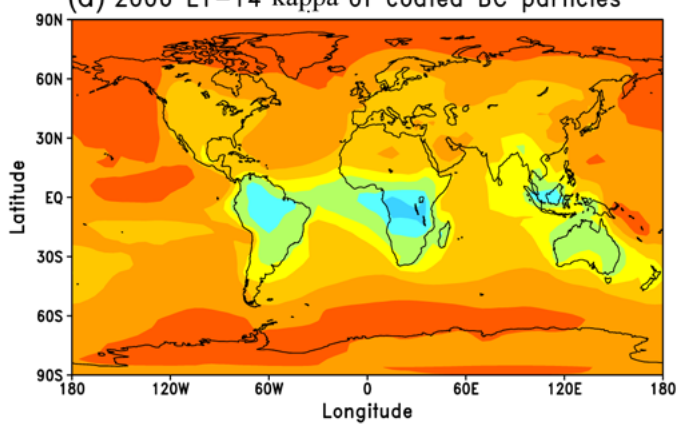

(f) 2006 L1-14 kappa of coated POC particles

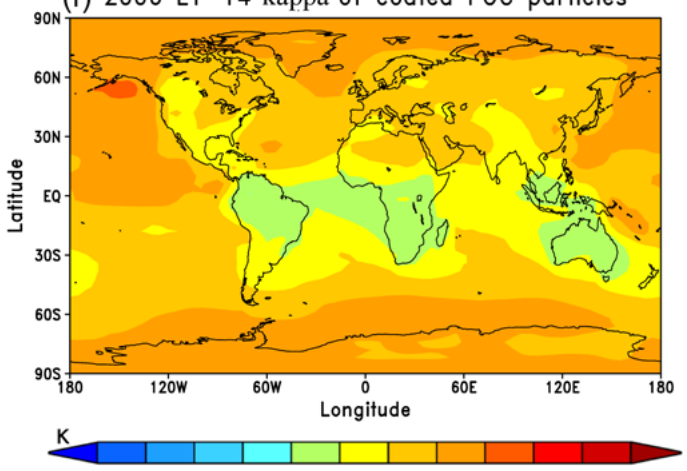

$\begin{array}{llllllllllll}0.01 & 0.05 & 0.1 & 0.15 & 0.2 & 0.3 & 0.4 & 0.5 & 0.6 & 0.7 & 0.8 & 1\end{array}$

Fig. 4. Ratio of total mass (core component + coated SS) to the mass of core component as well as hydroscopicity parameter $(\kappa)$ for SP, coated BC, and coated POC, averaged within the first $2 \mathrm{~km}$ (model layer 1-14) of atmosphere above the surface.

POC may be internally mixed BC which will affect the spatial distributions of $\kappa$ values for the resulting particles. In addition, $\kappa$ values for different POC and SOA compounds may have a wide range. Further observational and modeling studies are needed to assess how these uncertainties may impact AOD and DRF.

In summary, our modeling results presented above indicate that atmospheric particles are neither fully externally nor internally mixed. Globally averaged, about $71 \%$ of secondary species remain externally mixed but a small fraction of secondary species coated on BC and POC particles can significantly increase the size and $\kappa$ of these particles which has important impact on their optical properties and DRF. It should be pointed out that, while coating of secondary species has little impact on the size and optical properties of dust and sea- salt particles, it serves as a sink of secondary species in regions with high dust and sea-salt concentrations and thus has indirect impact on climate through the reduction of SP concentrations. The large spatial (Figs. 3-4) and temporal (not shown) variations of particle mixing states demonstrate the importance of treating detailed aerosol dynamic processes in the regional and global aerosol models.

\section{Global and regional aerosol optical properties: simulations and comparisons with measurements}

We have implemented the lookup tables described in Sect. 2 in GEOS-Chem-APM (Yu and Luo, 2009) and WRF-ChemAPM (Luo and Yu, 2011), enabling the optical properties of particles of different types to be calculated online in the 
model from the APM simulated particle properties described in Sect. 3. While the lookup tables have been designed according to the features of aerosols predicted by the APM, they cover a wide range of conditions and can be applied to other aerosol models for optical property calculation as well.

In the calculation of optical properties for coated BC and dust particles, the core-shell model assumes BC and dust particles have a spherical core, surrounded by a spherical shell composed of secondary species (sulfate, nitrate, ammonium, and SOA). Hygroscopic growth is important to determine particle wet size, which is needed to calculate particle optical properties. The amount of water associated with each particle type at a given RH is calculated based on volumeaverage values of hygroscopicity parameters $(\kappa)$ according to the formula given in Petters and Kreidenweis (2007). For secondary particles, coated sea salt particles, and coated primary organic particles, we use the volume-average of refractive index to calculate the optical properties of particles of a given wet size. The refractive indices for sulfate, ammonium, nitrate, SOA, POC, and water are according to the corresponding values given in Aouizerats et al. (2010). The refractive indices for sea salt, BC, and POC are based on values recommended by Krekov (1993), Bond et al. (2006), and Balkanski et al. (2007), respectively. The optical properties are calculated for particles in each bin of each type. For log-normal $\mathrm{BC}$ and POC particles, we discretize them into 20 bins during optical property calculation.

\subsection{Global aerosol optical properties - GEOS-Chem-APM simulations}

Figure 5 gives annual mean AOD horizontal distributions for 5 types of particles tracked by APM and the corresponding zonally averaged vertical profiles of the extinction coefficients at $\lambda=550 \mathrm{~nm}$. A combination of horizontal AOD distributions and vertical $Q_{\text {ext }}$ profiles gives us a 3-dimensional picture of the contributions of various particle types to AOD globally. The globally averaged AOD associated with SP, sea-salt, dust, coated BC, and coated POC are 0.066, 0.056, $0.019,0.006$, and 0.008 , respectively. SPs are present in highest concentrations in major continents and their immediate outflow regions, and clearly dominate AOD over major continents except dust source regions. Sea-salt is a dominant AOD contributor over oceans and polar regions while dust is important over major dust source and outflow regions (Sahara, middle east, north-western China, and Australia). Coated BC and POC particles make important contribution to AOD in major continents but their contributions are generally much smaller than that of SP except in East Asia. Vertically, most particle extinction occurs within $\sim 2 \mathrm{~km}$ above the surface. However, the vertical gradient of sea salt extinction coefficients is reduced at higher latitudes where sea salt particles make substantial contributions to extinction coefficients in the middle troposphere. The impact of dust particles extends to the middle troposphere as well. In the Arctic, all particles appear to make some contribution to extinction coefficients although SP and sea salt are the most important ones.

AOD have been observed in many locations through the AERONET (AErosol RObotic NETwork) program which is a federation of ground-based remote sensing aerosol networks established by NASA (Holben, 1998). The program provides a long-term, continuous and readily accessible public domain database of aerosol optical, microphysical and radiative properties for aerosol research and characterization. While ground based AERONET measurements provide data at high time resolution, they have limited spatial coverage. Satellite data, such as those from MODIS (Kaufman et al., 1997; Remer et al., 2005) and MISR (Martonchik et al., 1998), provide global coverage of AOD. It should be noted that AERONET, MODIS, and MISR AOD at visible wavelength are limited to local daytime under clear sky conditions. Consequently, care should be taken when comparing model results with observations, especially with regard to what periods the model results should be averaged. Due to the large grid box size in the global model $\left(4 \times 5^{\circ}\right.$, or around $400 \times 500 \mathrm{~km}$ in this study), most grid columns have some cloud fraction thus complete clear sky in the grid columns rarely occurs. It should be noted that the clear sky condition for AERONET, MODIS, and MISR is limited to a much smaller domain. For example, the spatial resolutions of MODIS (pixel size at nadir) range from 0.250 to $1 \mathrm{~km}$ for different channels. In this study, we treat a grid column as clear sky when the overall cloud fraction (CF) is $<50 \%$.

Figures 6 and 7 compare the modeled annual mean total AOD for all sky and clear sky (grid box overall $\mathrm{CF}<0.5$ ) with the observations from AERONET, MODIS, and MISR. The model captures the global spatial distributions of AOD, generally within a factor of 2 . It should be noted that there exist uncertainties in both model and observed values. The uncertainty in the measurements can be seen from the difference in the annual mean AERONET, MODIS, and MISR values which can also approach a factor of 2 or more. The difference is likely due to different instruments, retrieval algorithms, and periods of data available for averaging. Globally averaged AOD is 0.154 at all sky and is 0.127 under clear sky $(\mathrm{CF}<50 \%)$, with the difference even more significant at higher latitudes (Fig. 6). The effect of CF on AOD is largely associated with the hygroscopic growth of atmospheric particles as RH is generally higher during periods of higher $\mathrm{CF}$ within the grid box.

\subsection{Regional aerosol optical properties over the northeastern US - WRF-Chem-APM simulations}

The same APM model initially developed for GEOS-Chem (Yu and Luo, 2009) has been incorporated into WRF-Chem (Luo and Yu, 2011). Luo and Yu (2011) evaluated the performance of WRF-Chem-APM against measurements from the INTEX-A field campaign (summer, 2004) (Singh et al., 2006), and showed that the model can reveal urban and even 

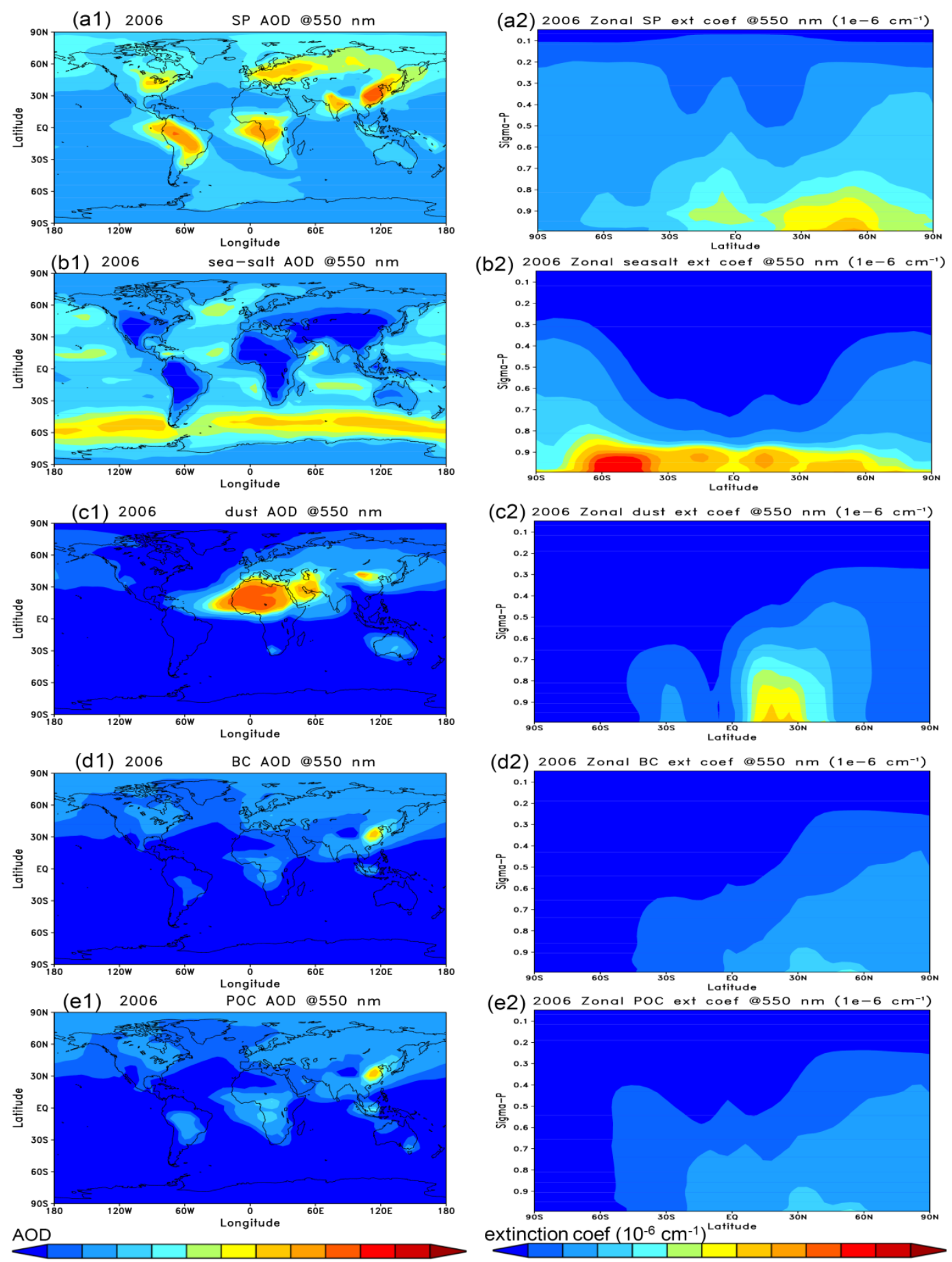

$\begin{array}{llllllllllll}0.005 & 0.01 & 0.04 & 0.07 & 0.1 & 0.13 & 0.16 & 0.2 & 0.3 & 0.5 & 0.7 & 1\end{array}$

$\begin{array}{llllllllllll}0.001 & 0.01 & 0.05 & 0.1 & 0.15 & 0.2 & 0.3 & 0.5 & 0.7 & 1 & 2 & 3\end{array}$

Fig. 5. Annual mean AOD horizontal distributions for 5 types of particles tracked by APM and the corresponding zonally averaged vertical profiles of the extinction coefficients at $\lambda=550 \mathrm{~nm}$.

plume scale aerosol formation and growth processes. We have carried out WRF-Chem-APM simulations for the period of 1-21 June 2008 (first 4 days as spin up) at $27 \times 27 \mathrm{~km}$ horizontal resolution. The domain covered the middle and eastern United States, extending approximately from latitudes
21.90 to $52.55^{\circ} \mathrm{N}$ and from longitudes 118.05 to $61.98^{\circ} \mathrm{W}$, with 140 grid nodes in the east-west direction and 108 in the north-south direction. The model has 34 vertical layers from the surface to $5 \mathrm{hPa}$, with finer resolution near the surface $(6$ 


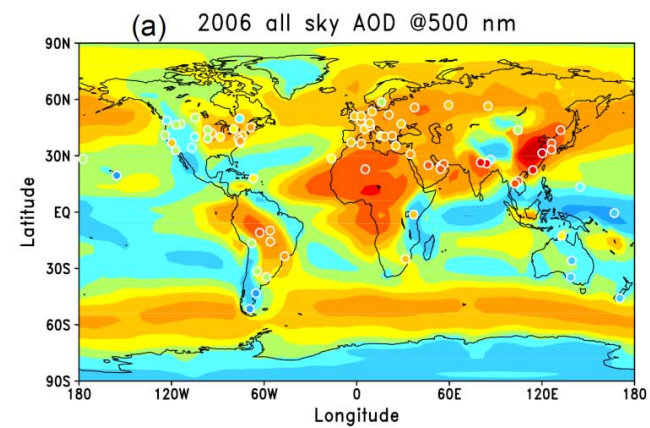

(b) 2006 clear sky $(C F<50 \%)$ AOD @500 nm

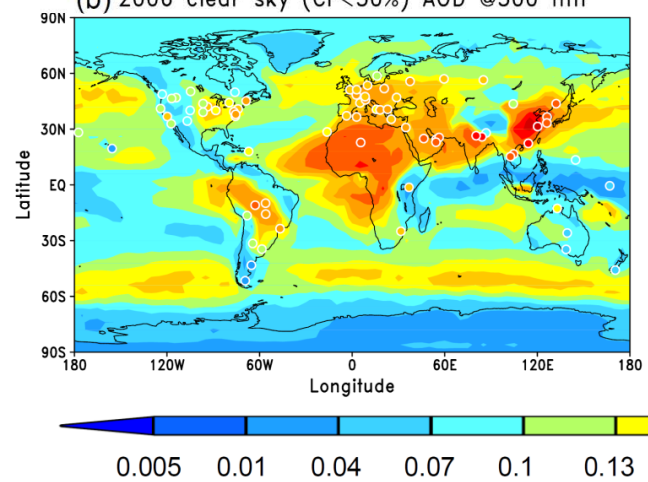

(c) $2006 \mathrm{MODIS} 1^{\circ} \times 1^{\circ} \mathrm{AOD}$

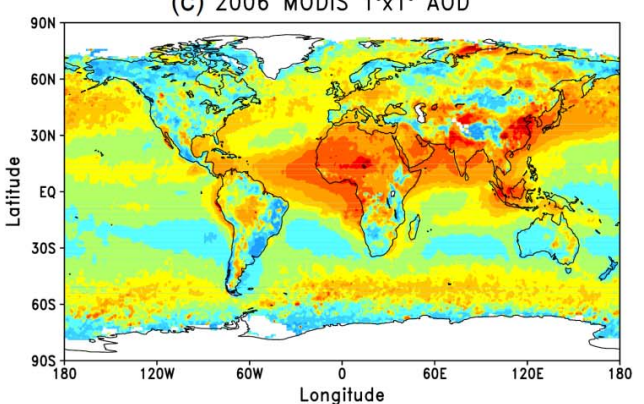

(d) $2006 \mathrm{MISR} 0.5^{\circ} \times 0.5^{\circ} \mathrm{AOD}$

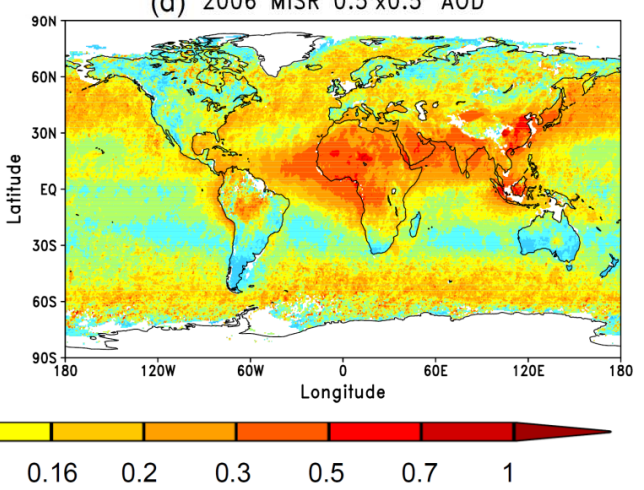

Fig. 6. Modeled annual mean total AOD at $500 \mathrm{~nm}$ for all sky and clear sky (grid box overall $\mathrm{CF}<0.5$ ) with the observations (at $500 \mathrm{~nm}$ ) from AERONET overlapped on modeled values, as well as values from MODIS (at $550 \mathrm{~nm}$ ) and MISR (at $555 \mathrm{~nm}$ ) for 2006. Only the Level 2.0 AEORNET data (cloud-screened and quality-assured) at $500 \mathrm{~nm}$ with at least 9 months of available data in 2006 (total 77 sites) are included in the comparison. MODIS (Moderate Resolution Imaging Spectroradiometer) AOD data is based on the monthly level-3 product from Aqua (MYD08_M3.051) with $1 \times 1^{\circ}$ degree resolution, and combined with deep blue product, which is the separate product specifically retrieved for the AOD over desert regions. MISR (Multi-angle Imaging SpectroRadiaometer) aerosol AOD data used here is the annual mean of monthly level-3 product with a resolution of $0.5 \times 0.5^{\circ}$.

(a) 2006, model 4x5, clear sky (CF $<50 \%)$

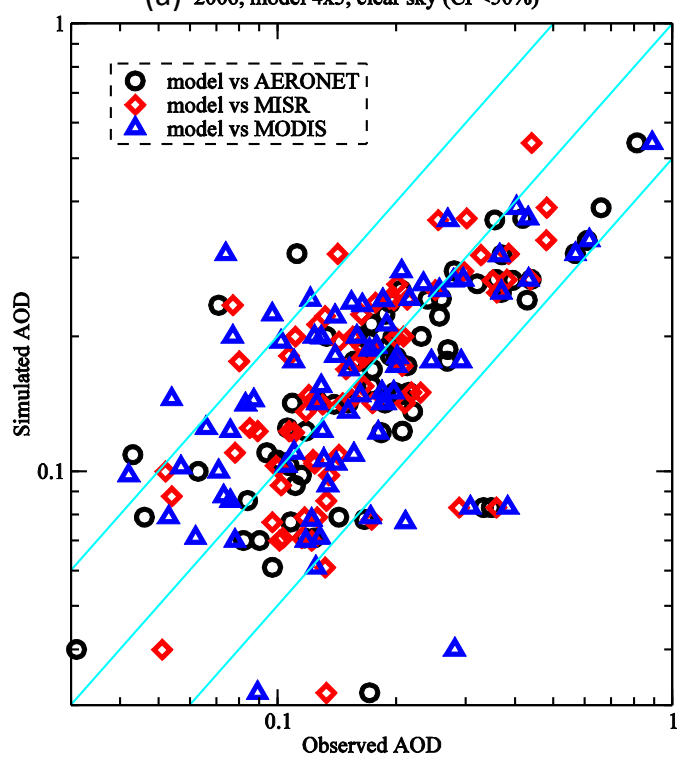

(b) 2006 , model $4 \times 5$

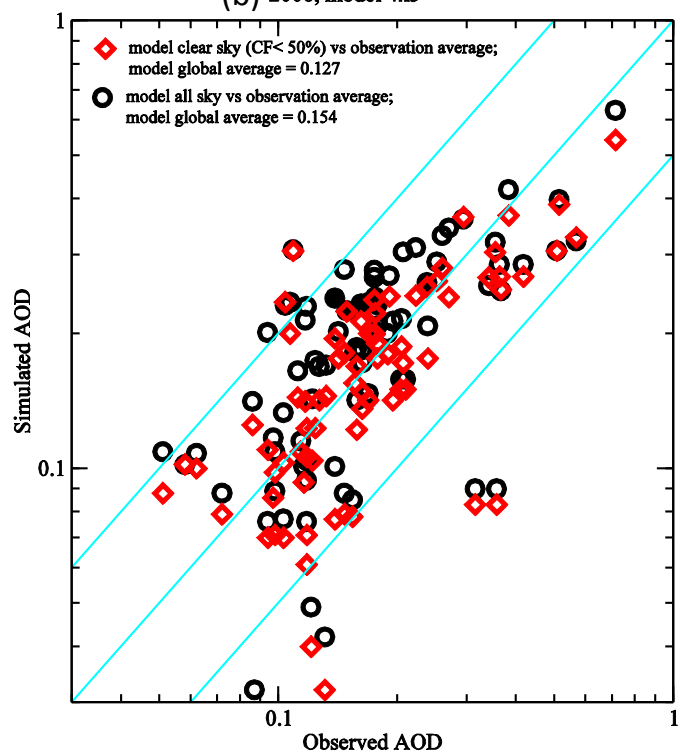

Fig. 7. Scatter plots of model predicted AOD versus observed AODs at the 77 AERONET sites, with panel (a) showing the modeled values under clear sky $(\mathrm{CF}<0.5)$ versus AERONET, MODIS, and MISR data and panel (b) presenting modeled values under all sky and partially cloudy sky conditions versus AERONET, MODIS, and MISR averaged values. 

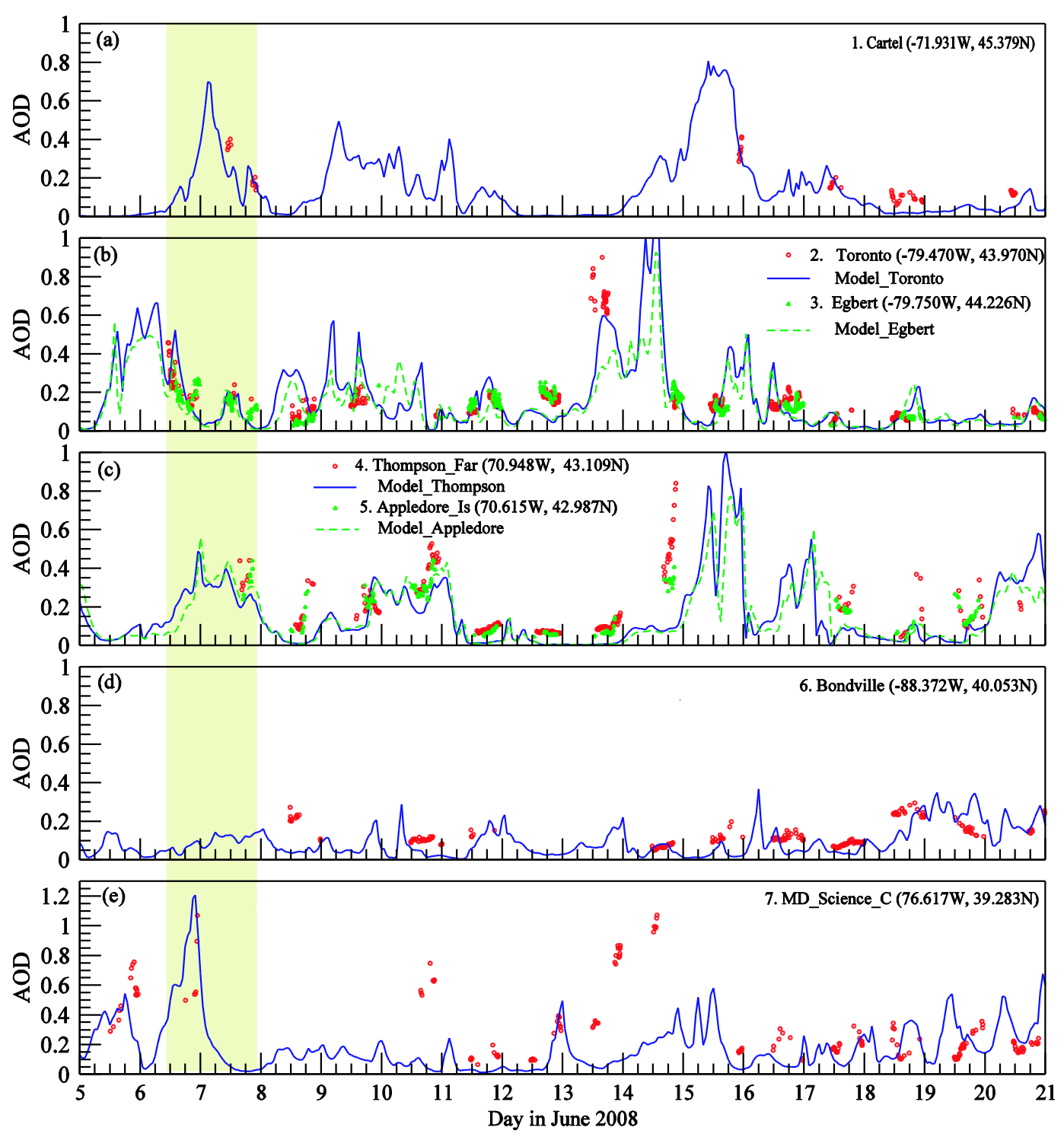

Fig. 8. Simulated and observed AOD at seven AERONET sites in northeast US during the period of 5-21 June 2008. The locations of sites are marked in Figs. 9-10. A two day period (6-7 June) used for detailed analysis is shaded.

layers within $\sim 1 \mathrm{~km}$ above surface). The present study focuses on the northeastern United States.

Figure 8 shows the simulated and observed AOD at seven AERONET sites and Figs. 9-10 present simulated particle formation rate, CN10SP, CN10PP, AOD, and AAOD during a two day period (6-7 June). In Fig. 8, AERONET sites close to each other (Toronto and Egbert, Thompson Farm and Appledore Island) are shown in the same panels. As discussed earlier, AERONET AOD data are limited to local daytime, clear sky conditions while the model provides AODs at all times. A comparison of simulated and observed AODs at the seven sites indicates that AOD at a given location can change significantly during a short period of time and, as we will show later, such a change appears to be associated with the crossing of particle plumes dominated by secondary particles. AOD at the seven sites are generally below 0.2 but periods of high AOD exceeding $\sim 0.6$ occur at all sites except Bondville. The high AOD periods generally last less than one day. Overall, the model captures the absolute values as well as the variations of AOD at the 7 AERONET sites, although substantial differences exist during some periods. The differences are likely due to uncertainties in the model (both meteorology and particle properties) as well as measurements. High AOD events on days 10-11 and 13-14 at station \#7 (MD_Science_C) missed by the model could also be caused by uncertainty in local emissions, as Station 7 is close to Washington DC and Baltimore MD and thus is subject to the influence of local aerosol plumes. 
(a)
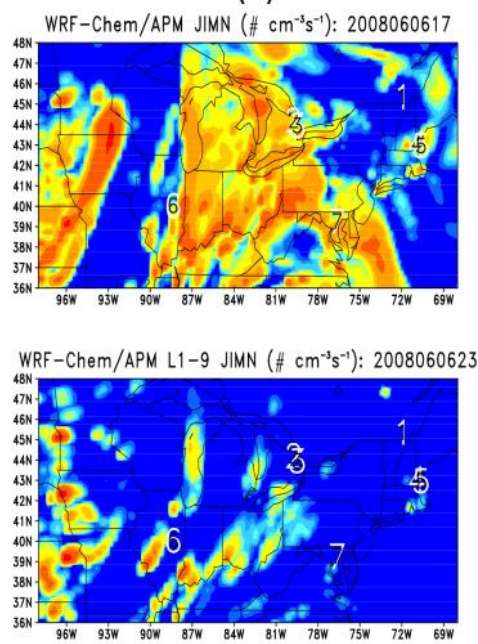

WRF-Chem/APM L1-9 JIMN (\# $\left.\mathrm{cm}^{-3} \mathrm{~s}^{-1}\right): 2008060705$

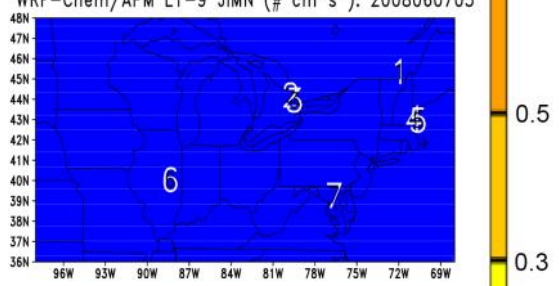

WRF-Chem/APM L1-9 JIMN (\# $\left.\mathrm{cm}^{-3} \mathrm{~s}^{-1}\right): 2008060711$

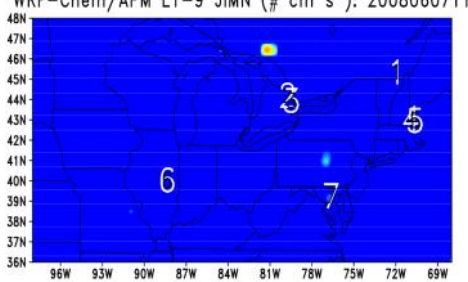

WRF-Chem/APM L1-9 JIMN (\# $\left.\mathrm{cm}^{-3} \mathrm{~s}^{-1}\right): 2008060717$

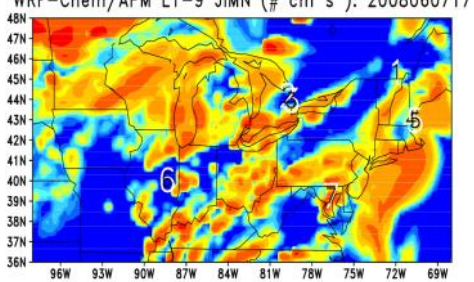

WRF-Chem/APM L1-9 JIMN (\# $\left.\mathrm{cm}^{-3} \mathrm{~s}^{-1}\right): 2008060723$

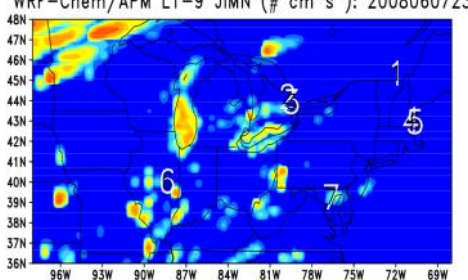

$5 e-3$ (b)
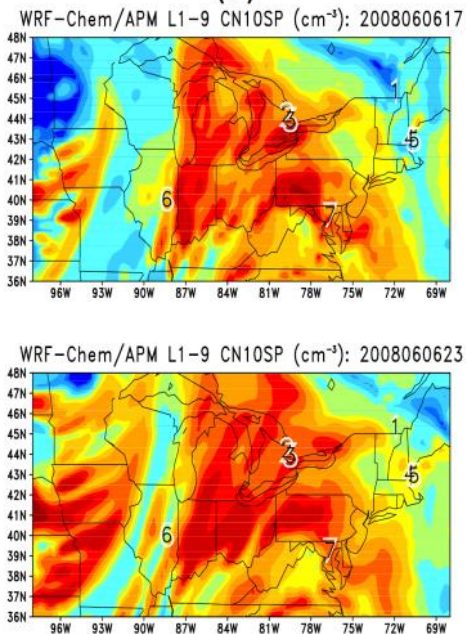

WRF-Chem/APM L1-9 CN10SP $\left(\mathrm{cm}^{-3}\right): 2008060705$

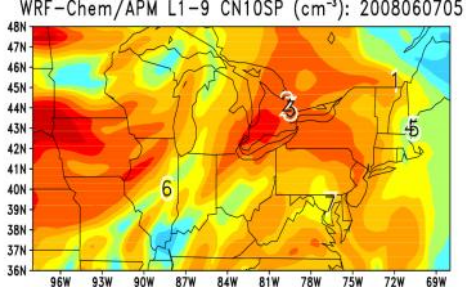

WRF-Chem/APM L1-9 CN10SP $\left(\mathrm{cm}^{-3}\right): 2008060711$
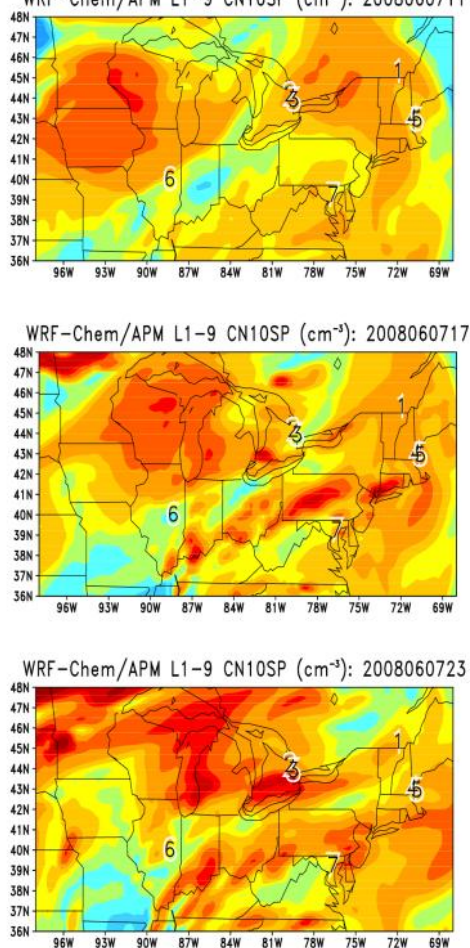

(c)

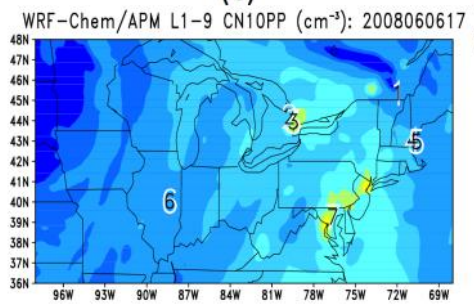

CN10SP

CN10PP
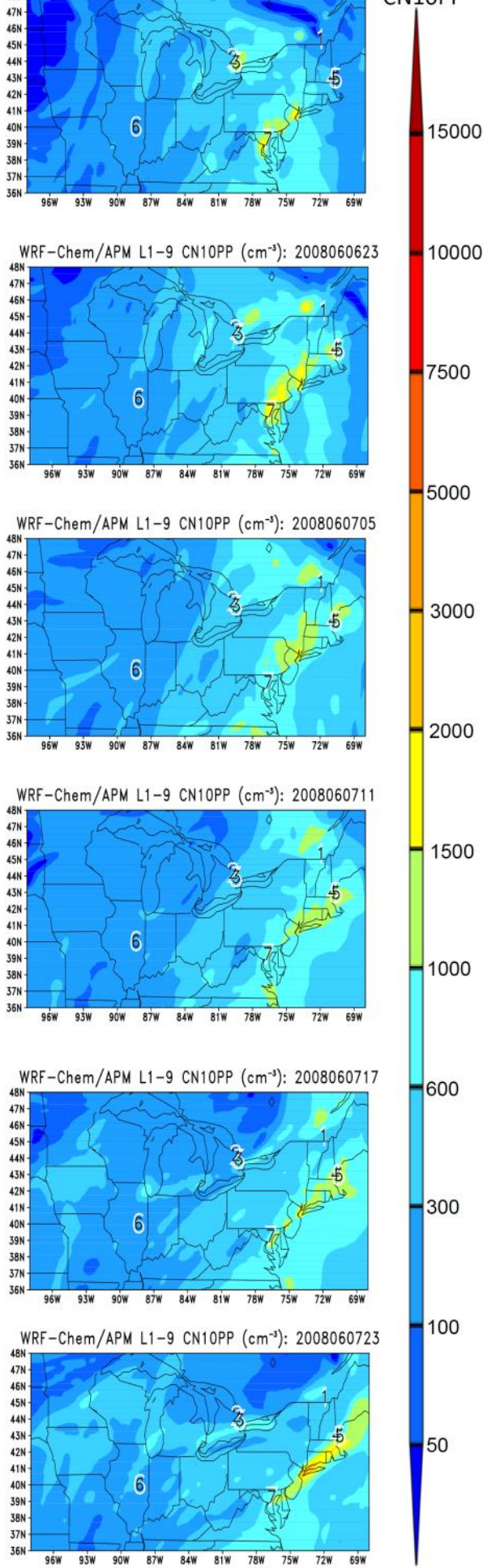

Fig. 9. Simulated (a) ion-mediated nucleation rate (JIMN) and number concentrations of (b) secondary and (c) primary particles larger than $10 \mathrm{~nm}$ (CN10SP, CN10PP) in the northeast US, averaged within the first two km above the surface (model layer 1-9) during a two day period (6-7 June). Number 1-7 overlayed on each panel mark the locations of seven AERONET sites given in Fig. 8. 
(a)
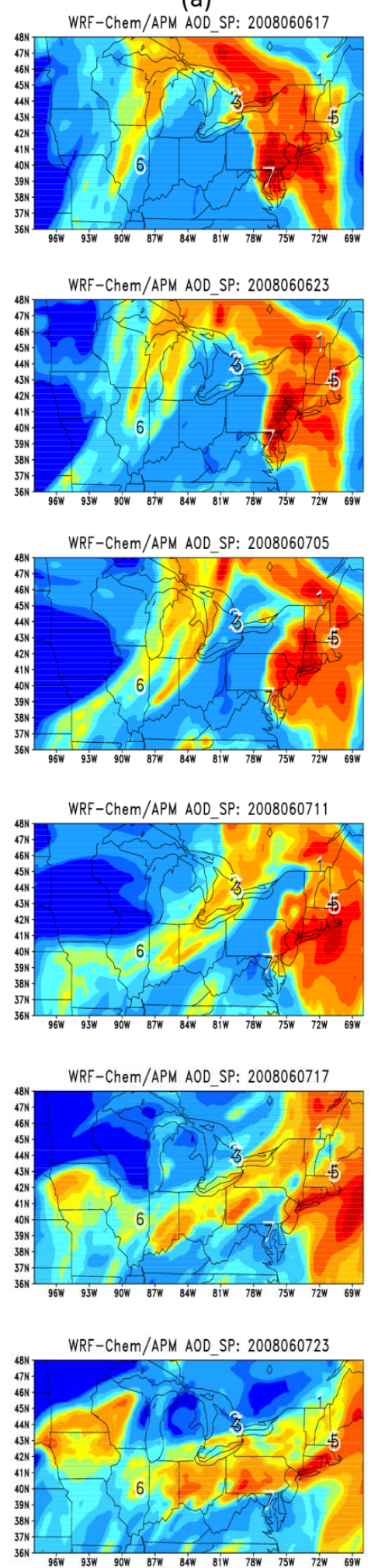

(b)
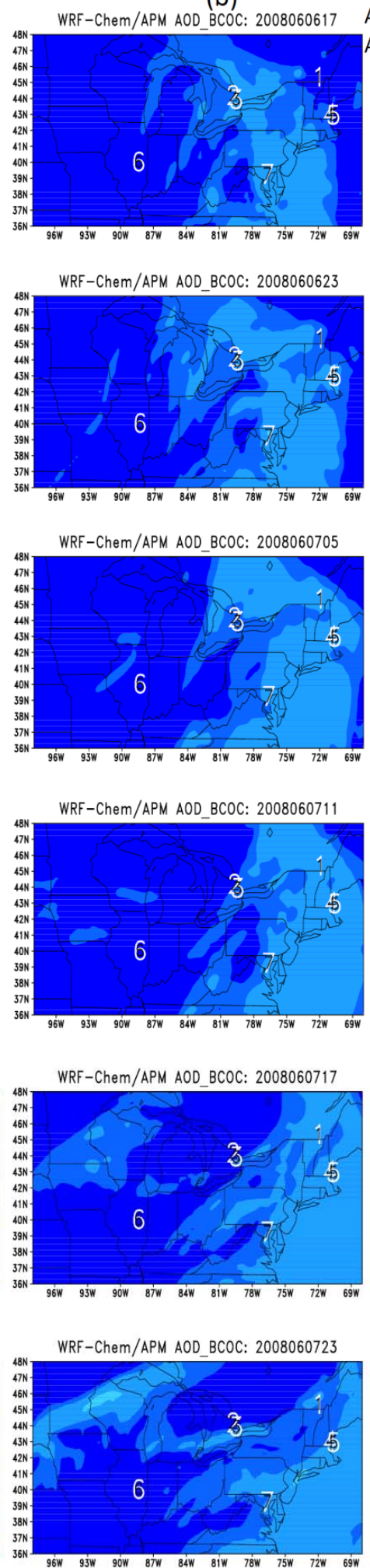

(c)

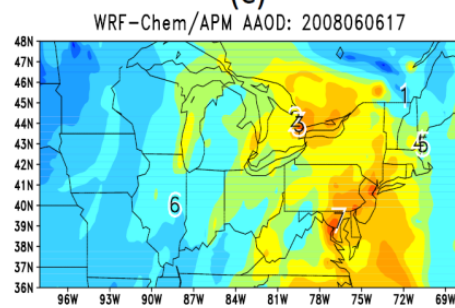
AAOD

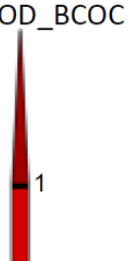

0.7

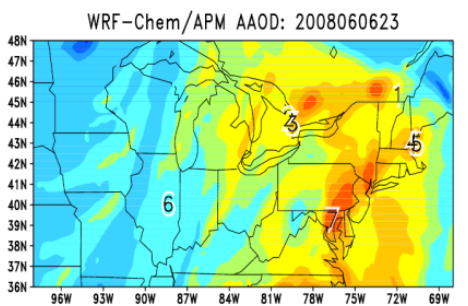

0.05

0.02
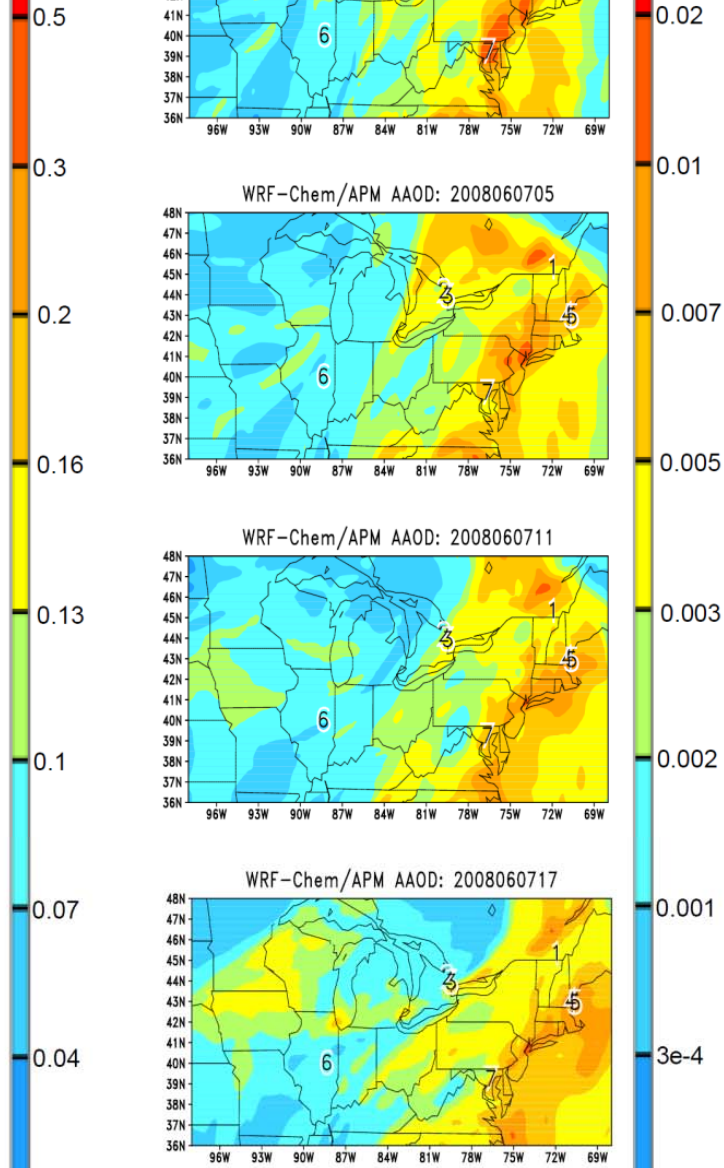

$-0.04$

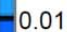

$-0.01$

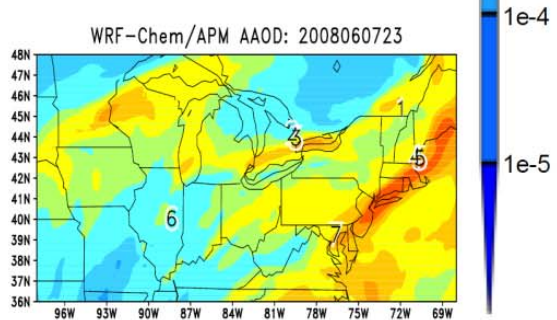

Fig. 10. Same as Fig. 9 but for, AOD associated with (a) SP and (b) coated BC and POC (BCOC), and (c) AAOD. 
To illustrate the cause of AOD variations and major contributions, we examine in detail the evolution of particle properties and AODs over the northeastern US during a two-day period (6-7 June) in Figs. 9-10. WRF-Chem-APM simulations indicate that AOD over the northeastern US is dominated by SP, which is consistent with GEOS-Chem-APM annual mean results (Fig. 5). In the model, the new particle (or SP) formation rate was calculated based on a physics-based IMN mechanism (Yu, 2010) which has been shown to be supported by state-of-art field measurements in the boreal forest (Yu and Turco, 2011). It is clear from Fig. 9a that IMN leads to significant production of SP during the daytime in the lower troposphere over the northeastern US. The nucleation rates have large spatial variations and the model with $27 \times 27 \mathrm{~km}$ resolution appears to resolve the nucleation plumes. The higher nucleation rates over certain regions on a particular day are mainly associated with high sulfuric acid vapor concentrations there (as a result of photochemistry). All the SPs shown in Fig. 9b, with peak values exceeding $10^{4} \mathrm{~cm}^{-3}$, are formed via IMN. Due to the time needed to grow the nucleated particles to larger than $10 \mathrm{~nm}$, CN10_SP given in Fig. 9b is higher at GMT $=23$ than at GMT $=17$. During local night time, CN10_SP decreases as a result of transport and scavenging. The number concentrations of primary particles over the northeastern US, dominated by BCOC (ie., BC + POC), range from a few hundreds per $\mathrm{cm}^{3}$ in western parts of the domain to $1000-2000 \mathrm{~cm}^{-3}$ in the Northeast Corridor (Washington, DC, Baltimore, Philadelphia, New York, and Boston regions). These primary particles are coated by secondary species of various amounts (not shown) and their AOD is in the range of 0.005-0.04 in the areas where their number concentrations are relatively high $\left(>300 \mathrm{~cm}^{-3}\right)$. Spatial distribution of AAOD (Fig. 10c) is close to that of BCOC AOD (Fig. 10b) and number concentrations of BCOC particles (Fig. 9c) as BC particles dominate the absorption of atmospheric particles. In the regions with relatively high $\mathrm{BC}$ concentrations, AAOD reaches up to $\sim 0.003-0.01$ on the two days shown. It is noteworthy that the regions of high AAOD differ significantly with those of high AOD (especially within the western part of the domain), indicating different source regions of $\mathrm{BC}$ and SP particles.

Another interesting detail is that the spatial distributions of SP concentrations and AOD for 6 June differ substantially from those for 7 June, signaling strong day-to-day variations of particle concentrations and AOD. As it is clear from AERONET data, AOD can increase or drop dramatically during a short period of time (a few hours). Our simulations indicate such dramatic change appears to be associated with the crossing of a high AOD plume dominated by SP. For example, AERONET AOD data show significant decreases at the Toronto and MD-Science_C sites on the afternoon of 6 June. The model captures such a drop and the simulation results (Figs. 9 and 10) suggest that the drop was due to the passage of high SP and AOD plumes over the two sites. It is interesting to note that there exists a weak peak in the middle (GMT time) of 7 June at Toronto and Egbert sites, and the model captures this peak which was a result of passage of another AOD plume from the west.

\section{Summary}

There exist large uncertainties in the present modeling of physical, chemical, and optical properties of atmospheric particles, which contribute to the uncertainties in aerosol RF assessment and climate change projection. We have recently developed a size-resolved APM model and incorporated it into GEOS-Chem and WRF-Chem. The APM model is designed to capture the main particle properties (sizes, compositions, coating of primary particles by volatile species, etc.) important for their RF with low computational costs. In this study, we use important aerosol information resolved by the APM model to calculate and investigate global and regional distributions of aerosol optical properties. A computationally efficient scheme, in term of lookup tables derived from core-shell model, has been developed to calculate online the aerosol optical properties in the framework of GEOS-ChemAPM and WRF-Chem-APM. The simulated aerosol optical properties are analyzed and compared with AERONET, MODIS, and MISR measurements. The key findings are summarized below.

1. Theoretical analysis of key parameters controlling aerosol optical properties suggests the importance of resolving size, composition, and mixing state explicitly of atmospheric particles, especially secondary, $\mathrm{BC}$, and primary OC particles.

2. Model results suggest that atmospheric particles are neither fully externally nor internally mixed. Secondary species reside mainly in SP (60-90\%) in most parts of the globe, but a large fraction (up to 50-80\%) can become coated on various primary particles in certain regions. Globally averaged, about $71 \%$ of secondary species remain externally mixed but a small fraction of secondary species coated on BC and POC particles can significantly increase the size and $\kappa$ of these particles which has important impact on their optical properties and DRF.

3. The globally averaged AOD associated with SP, seasalt, dust, coated BC, and coated POC are 0.066, 0.056, $0.019,0.006$, and 0.008 , respectively. SPs are generally confined to major continents and their immediate outflow regions, which clearly dominate AOD over major continents except dust source regions. Coated BC and $\mathrm{POC}$ particles make important contribution to AOD over major continents but their contributions are generally much smaller than that of SP except in East Asia. Vertically, most particle extinction occurs within $\sim 2 \mathrm{~km}$ of the surface. 
4. The GEOS-Chem-APM model captures the global spatial distributions of AOD derived from AERONET, MODIS, and MISR measurements, generally within a factor of 2. Our comparison of modeled AOD at all sky and clear (or partially cloudy) sky indicates that the amount of cloud cover in the grid box has a strong impact on AOD and care should be taken when comparing model results with observations.

5. A comparison of WRF-Chem-APM predicted AODs over the northeastern US in June 2008 with those from seven AERONET sites indicates that the WRF-ChemAPM model captures reasonably well the absolute values as well as the variations of AOD at the 7 AERONET sites during the simulated periods, although substantial differences exit during some periods. AOD at a given location can change significantly during a short period of time and we show that such a change appears to be associated with the crossing of particle plumes dominated by secondary particles. WRF-Chem-APM simulations indicate that AOD over the northeastern US is dominated by secondary particles formed via ion-mediated nucleation, which is consistent with GEOS-Chem-APM results.

The online aerosol optical property calculation capability of the APM module in GEOS-Chem and WRF-Chem enables us to compare APM aerosol simulations with a much larger data set as well as study the impacts of various processes on aerosol optical properties and DRF at different spatial and temporal scales, which will be the subject of future investigations.

Acknowledgements. This study is supported by DOE under grant DE-SC0002199 and NSF under grant AGS-0942106. The data for AOD from MODIS and MISR were downloaded using the GES-DISC Interactive Online Visualization and Analysis Infrastructure, a part of the NASA's Goddard Earth Sciences Data and Information Services Center and AERONET data were obtained from NASA Goddard Space Flight Center. The MODIS L1B data were obtained through the online Data Pool at the NASA Land Processes Distributed Active Archive Center (LP DAAC), USGS/Earth Resources Observation and Science (EROS) Center, Sioux Falls, South Dakota. The GEOS-Chem model is managed by the Atmospheric Chemistry Modeling Group at Harvard University with support from NASA's Atmospheric Chemistry Modeling and Analysis Program. The authors thank the WRF-Chem development and management teams for WRF-Chem version 3.1 used in this study.

Edited by: J. Quaas

\section{References}

Ackerman, T. P. and Toon O. B.: Absorption of visible radiation in atmosphere containing mixtures of absorbing and non-absorbing particles, Appl. Opt., 20, 3661-3668, 1981.

Alexander, D. T. L., Crozier, P. A., and Anderson, J. R.: Brown carbon spheres in east asian outflow and their optical properties, Science, 321, 833-836, 2008.

Aouizerats, B., Thouron, O., Tulet, P., Mallet, M., Gomes, L., and Henzing, J. S.: Development of an online radiative module for the computation of aerosol optical properties in 3-D atmospheric models: validation during the EUCAARI campaign, Geosci. Model Dev., 3, 553-564, doi:10.5194/gmd-3-553-2010, 2010.

Balkanski, Y., Schulz, M., Claquin, T., and Guibert, S.: Reevaluation of Mineral aerosol radiative forcings suggests a better agreement with satellite and AERONET data, Atmos. Chem. Phys., 7, 81-95, doi:10.5194/acp-7-81-2007, 2007.

Bauer, S. E., Wright, D. L., Koch, D., Lewis, E. R., McGraw, R., Chang, L.-S., Schwartz, S. E., and Ruedy, R.: MATRIX (Multiconfiguration Aerosol TRacker of mIXing state): an aerosol microphysical module for global atmospheric models, Atmos. Chem. Phys., 8, 6003-6035, doi:10.5194/acp-8-60032008, 2008.

Bey, I., Jacob, D., Yantosca, R., Logan, J., Field, B., Fiore, A., Li, Q., Liu, H., Mickley, L., and Schultz, M.: Global modeling of tropospheric chemistry with assimilated meteorology: Model description and evaluation, J. Geophys. Res., 106, 23073-23096, 2001.

Bond, T. C., Habib, G., and Bergstrom, R. W.: Limitations in the enhancement of visible light ab-sorption due to mixing state, J. Geophys. Res., 111, D20211, doi:10.1029/2006JD007315, 2006.

Chin, M., Kahn, R. A., and Schwart, S. E. (Eds.): Atmospheric Aerosol Properties and Climate Impacts, A Report by the U.S. Climate Change Science Program and the Subcommittee on Global Change Research, National Aeronautics and Space Administration, Washington, D.C., USA, 2009.

Chung, S. H. and Seinfeld, J. H.: Global distribution and climate forcing of carbonaceous aerosols, J. Geophys. Res., 107, 4407, doi:10.1029/2001JD001397, 2002.

Fountoukis, C. and Nenes, A.: ISORROPIA II: a computationally efficient thermodynamic equilibrium model for $\mathrm{K}^{+}-$ $\mathrm{Ca}^{2+}-\mathrm{Mg}^{2+}-\mathrm{NH}_{4}^{+}-\mathrm{Na}^{+}-\mathrm{SO}_{4}^{2-}-\mathrm{NO}_{3}^{-}-\mathrm{Cl}^{-}-\mathrm{H}_{2} \mathrm{O}$ aerosols, Atmos. Chem. Phys., 7, 4639-4659, doi:10.5194/acp-7-4639-2007, 2007.

Holben, B: AERONET: A federated instrument network and data archived for aerosol characterization, Remote. Sens. Envion., 66, 1-16, 1998 .

Intergovermental Panel on Climate Change (IPCC): Fourth Assessment Report, Cambridge Univ. Press, New York, 2007.

Jaeglé, L., Quinn, P. K., Bates, T. S., Alexander, B., and Lin, J.-T.: Global distribution of sea salt aerosols: new constraints from in situ and remote sensing observations, Atmos. Chem. Phys., 11, 3137-3157, doi:10.5194/acp-11-3137-2011, 2011.

Jacobson, M. Z.: Strong radiative heating due to the mixing state of black carbon in atmospheric aerosol, Nature, 409, 695-697, 2001.

Jimenez, J. L., Canagaratna, M. R., Donahue, N. M., Prevot, A. S. H., Zhang, Q., Kroll, J. H., DeCarlo, P. F., Allan, J. D., Coe, 
H., Ng, N. L., Aiken, A. C., Docherty, K. D., Ulbrich, I. M., Grieshop, A. P., Robinson, A. L., Duplissy, J., Smith, J. D., Wilson, K. R., Lanz, V. A., Hueglin, C., Sun, Y. L., Tian, J., Laaksonen, A., Raatikainen, T., Rautiainen, J., Vaattovaara, P., Ehn, M., Kulmala, M., Tomlinson, J. M., Collins, D. R., Cubison, M. J., Dunlea, E. J., Huffman, J. A., Onasch, T. B., Alfarra, M. R., Williams, P. I., Bower, K., Kondo, Y., Schneider, J., Drewnick, F., Borrmann, S., Weimer, S., Demerjian, K., Salcedo, D., Cottrell, L., Griffin, R., Takami, A., Miyoshi, T., Hatakeyama, S., Shimono, A., Sun, J. Y, Zhang, Y. M., Dzepina, K., Kimmel, J. R., Sueper, D., Jayne, J. T., Herndon, S. C., Trimborn, A. M., Williams, L. R., Wood, E. C., Kolb, C. E., Middlebrook, A. M., Baltensperger, U., and Worsnop, D. R.: Evolution of Organic Aerosols in the Atmosphere, Science, 326, 1525, doi:10.1126/science.1180353, 2009.

Kaufman, Y. J., Tanré, D., Remer, L. A., Vermote, E. F., Chu, A., and Holben, B. N.: Operational remote sensing of tropospheric aerosol over the land from EOS-MODIS, J. Geophys. Res., 102, 17051-17061, 1997.

Kinne, S., Schulz, M., Textor, C., Guibert, S., Balkanski, Y., Bauer, S. E., Berntsen, T., Berglen, T. F., Boucher, O., Chin, M., Collins, W., Dentener, F., Diehl, T., Easter, R., Feichter, J., Fillmore, D., Ghan, S., Ginoux, P., Gong, S., Grini, A., Hendricks, J., Herzog, M., Horowitz, L., Isaksen, I., Iversen, T., Kirkevåg, A., Kloster, S., Koch, D., Kristjansson, J. E., Krol, M., Lauer, A., Lamarque, J. F., Lesins, G., Liu, X., Lohmann, U., Montanaro, V., Myhre, G., Penner, J., Pitari, G., Reddy, S., Seland, O., Stier, P., Takemura, T., and Tie, X.: An AeroCom initial assessment - optical properties in aerosol component modules of global models, Atmos. Chem. Phys., 6, 1815-1834, doi:10.5194/acp-6-1815-2006, 2006.

Koch, D., Schulz, M., Kinne, S., McNaughton, C., Spackman, J. R., Balkanski, Y., Bauer, S., Berntsen, T., Bond, T. C., Boucher, O., Chin, M., Clarke, A., De Luca, N., Dentener, F., Diehl, T., Dubovik, O., Easter, R., Fahey, D. W., Feichter, J., Fillmore, D., Freitag, S., Ghan, S., Ginoux, P., Gong, S., Horowitz, L., Iversen, T., Kirkevåg, A., Klimont, Z., Kondo, Y., Krol, M., Liu, X., Miller, R., Montanaro, V., Moteki, N., Myhre, G., Penner, J. E., Perlwitz, J., Pitari, G., Reddy, S., Sahu, L., Sakamoto, H., Schuster, G., Schwarz, J. P., Seland, Ø., Stier, P., Takegawa, N., Takemura, T., Textor, C., van Aardenne, J. A., and Zhao, Y.: Evaluation of black carbon estimations in global aerosol models, Atmos. Chem. Phys., 9, 9001-9026, doi:10.5194/acp-9-9001-2009, 2009.

Krekov, M.: Aerosols Effects on Climate, Univerity of Arizona Press, USA, 9-72, 1993.

Luo, G. and Yu, F.: Simulation of particle formation and number concentration over the Eastern United States with the WRFChem + APM model, Atmos. Chem. Phys., 11, 11521-11533, doi:10.5194/acp-11-11521-2011, 2011.

Ma, X., Yu, F., and Luo, G.: Aerosol direct radiative forcing based on GEOS-Chem-APM and uncertainties, Atmos. Chem. Phys., 12, 5563-5581, doi:10.5194/acp-12-5563-2012, 2012.

Martonchik, J. V., Diner, D. J., Kahn, R. A., Ackerman, T. P., Verstraete, M. M., Pinty, B., and Gordon, H. R.: Techniques for the retrieval of aerosol properties over land and ocean using multiangle imaging, IEEE T. Geosci. Remote Sens., 36, 1212-1227, 1998.
Merikanto, J., Spracklen, D. V., Pringle, K. J., and Carslaw, K. S.: Effects of boundary layer particle formation on cloud droplet number and changes in cloud albedo from 1850 to 2000, Atmos. Chem. Phys., 10, 695-705, doi:10.5194/acp-10-695-2010, 2010.

Petters, M. D. and Kreidenweis, S. M.: A single parameter representation of hygroscopic growth and cloud condensation nucleus activity, Atmos. Chem. Phys., 7, 1961-1971, doi:10.5194/acp-71961-2007, 2007.

Pierce, J. R., Chen, K., and Adams, P. J.: Contribution of primary carbonaceous aerosol to cloud condensation nuclei: processes and uncertainties evaluated with a global aerosol microphysics model, Atmos. Chem. Phys., 7, 5447-5466, doi:10.5194/acp-75447-2007, 2007.

Remer, L. A., Kaufman, Y. J., Tanré, D., Mattoo, S., Chu, D. A., Martins, J. V., Li, R.-R., Ichoku, C., Levy, R. C., Kleidman, R G., Eck, T. F., Vermote, E., and Holben, B. N.: The MODIS algorithm, products and validation. J. Atmos. Sci., 62, 947-973, 2005.

Schulz, M., Textor, C., Kinne, S., Balkanski, Y., Bauer, S., Berntsen, T., Berglen, T., Boucher, O., Dentener, F., Guibert, S., Isaksen, I. S. A., Iversen, T., Koch, D., Kirkevåg, A., Liu, X., Montanaro, V., Myhre, G., Penner, J. E., Pitari, G., Reddy, S., Seland, Ø., Stier, P., and Takemura, T.: Radiative forcing by aerosols as derived from the AeroCom present-day and pre-industrial simulations, Atmos. Chem. Phys., 6, 5225-5246, doi:10.5194/acp-65225-2006, 2006.

Shapiro, E. L., Szprengiel, J., Sareen, N., Jen, C. N., Giordano, M. R., and McNeill, V. F.: Light-absorbing secondary organic material formed by glyoxal in aqueous aerosol mimics, Atmos. Chem. Phys., 9, 2289-2300, doi:10.5194/acp-9-2289-2009, 2009.

Singh, H. B., Brune, W. H., Crawford, J. H., Jacob, D. J., and Russell, P. B.: Overview of the summer 2004 Intercontinental Chemical Transport Experiment - North America (INTEX-A), J. Geophys. Res., 111, D24S01, doi:10.1029/2006JD007905, 2006.

Spracklen, D. V., Carslaw, K. S., Kulmala, M., Kerminen, V.-M., Sihto, S.-L., Riipinen, I., Merikanto, J., Mann, G. W., Chipperfield, M. P., Wiedensohler, A., Birmili, W., and Lihavainen, H.: Contribution of particle formation to global cloud condensation nuclei concentrations, Geophys. Res. Lett., 35, L06808, doi:10.1029/2007GL033038, 2008.

Stier, P., Feichter, J., Kinne, S., Kloster, S., Vignati, E., Wilson, J., Ganzeveld, L., Tegen, I., Werner, M., Balkanski, Y., Schulz, M., Boucher, O., Minikin, A., and Petzold, A.: The aerosol-climate model ECHAM5-HAM, Atmos. Chem. Phys., 5, 1125-1156, doi:10.5194/acp-5-1125-2005, 2005.

Textor, C., Schulz, M., Guibert, S., Kinne, S., Balkanski, Y., Bauer, S., Berntsen, T., Berglen, T., Boucher, O., Chin, M., Dentener, F., Diehl, T., Feichter, J., Fillmore, D., Ginoux, P., Gong, S., Grini, A., Hendricks, J., Horowitz, L., Huang, P., Isaksen, I. S. A., Iversen, T., Kloster, S., Koch, D., Kirkevåg, A., Kristjansson, J. E., Krol, M., Lauer, A., Lamarque, J. F., Liu, X., Montanaro, V., Myhre, G., Penner, J. E., Pitari, G., Reddy, M. S., Seland, Ø., Stier, P., Takemura, T., and Tie, X.: The effect of harmonized emissions on aerosol properties in global models an AeroCom experiment, Atmos. Chem. Phys., 7, 4489-4501, doi:10.5194/acp-7-4489-2007, 2007.

Wang, M. and Penner, J. E.: Aerosol indirect forcing in a global model with particle nucleation, Atmos. Chem. Phys., 9, 239-260, doi:10.5194/acp-9-239-2009, 2009. 
Yu, F.: Ion-mediated nucleation in the atmosphere: Key controlling parameters, implications, and look-up table, J. Geophy. Res., 115, D03206, doi:10.1029/2009JD012630, 2010.

Yu, F.: A secondary organic aerosol formation model considering successive oxidation aging and kinetic condensation of organic compounds: global scale implications, Atmos. Chem. Phys., 11, 1083-1099, doi:10.5194/acp-11-1083-2011, 2011.

Yu, F. and Luo, G.: Simulation of particle size distribution with a global aerosol model: contribution of nucleation to aerosol and CCN number concentrations, Atmos. Chem. Phys., 9, 76917710, doi:10.5194/acp-9-7691-2009, 2009.

Yu, F. and Turco, R. P.: The size-dependent charge fraction of sub-3$\mathrm{nm}$ particles as a key diagnostic of competitive nucleation mechanisms under atmospheric conditions, Atmos. Chem. Phys., 11, 9451-9463, doi:10.5194/acp-11-9451-2011, 2011.
Yu, F., Luo, G., Bates, T., Anderson, B., Clarke, A., Kapustin, V., Yantosca, R., Wang, Y., and Wu, S.: Spatial distributions of particle number concentrations in the global troposphere: Simulations, observations, and implications for nucleation mechanisms, J. Geophys. Res., 115, D17205, doi:10.1029/2009JD013473, 2010.

Yu, F., Luo, G., Turco, R. P., Ogren, J. A., and Yantosca, R. M.: Decreasing particle number concentrations in a warming atmosphere and implications, Atmos. Chem. Phys., 12, 2399-2408, doi:10.5194/acp-12-2399-2012, 2012. 